\title{
Education, Health and Mortality: Evidence from a Social Experiment*
}

\author{
Costas Meghir ${ }^{1}$, Mårten Palme ${ }^{2}$, Emilia Simeonova $^{3}$
}

Keywords: Causal effects of education; Compulsory schooling laws; Comprehensive school reforms; Education reform; Returns to schooling;

JEL codes: I12, I18, I21

\footnotetext{
*We are grateful for comments from Douglas Almond, Anne Case, Meltem Daisal, Angus Deaton, Ilona Koupil, Amanda Kowalski, Ilyana Kuziemko, Adriana Lleras-Muney, Doug Miller, Sendhil Mullainathan, Torsten Persson Diane Schanzenbach and Kosali Simon as well as from participants in seminars at Tufts University, Princeton University, the University of New Hampshire, Case Western Reserve University, SOFI, CHESS and the IIES at Stockholm University, the 2011 Nordic Summer Institute in Labor Economics at the Faroe Islands, the NBER Summer Institute, the 2012 CeMENT meetings in Chicago and the 2011 IHEA conference in Toronto. Financial support from the IFAU is gratefully acknowledged.

${ }^{1}$ Department of Economics, Yale University Box 208264 New Haven, CT 06520-8264, USA; IFS and ESRC. Email: C.Meghir@yale.edu.

${ }^{2}$ Department of Economics, Stockholm University, SE-106 91 Stockholm, Sweden. E-mail: Marten.Palme@ne.su.se.

${ }^{3}$ Department of Economics, Tufts University and NBER; 355 Wallace Hall, Princeton University, Princeton, NJ 08542; email: Emilia.simeonova@gmail.com
} 


\begin{abstract}
We study the effect of a compulsory education reform in Sweden on adult health and mortality. The reform was implemented by municipalities between 1949 and 1962 as a social experiment and implied an extension of compulsory schooling from 7 or 8 years depending on municipality to 9 years nationally. We use detailed individual data on education, hospitalizations, labor force participation and mortality for Swedes born between 1946 and 1957. Individual level data allow us to study the effect of the education reform on three main groups of outcomes: (i) mortality until age 60 for different causes of death; (ii) hospitalization by cause and (iii) exit from the labor force primarily through the disability insurance program. The results show reduced male mortality up to age fifty for those assigned to the reform, but these gains were erased by increased mortality later on. We find similar patterns in the probability of being hospitalized and the average costs of inpatient care. Men who acquired more education due to the reform are less likely to retire early.
\end{abstract}




\section{Introduction}

The strong correlation between socio-economic status (SES) and health is one of the most recognized and studied in the social sciences. Economists have pointed at differences in resources, preferences and knowledge associated with different SES groups as possible explanations (see e.g. Grossman, 2006, for an overview). However, a causal link between any of these factors and later life health is hard to prove and the relative importance of different contributing factors is far from clear. A series of studies (e.g. Lleras-Muney, 2005; Oreopoulos, 2006; Clark and Royer, 2010), use regional differences in compulsory schooling laws or changes in national legislations on compulsory schooling as a source of exogenous variation in educational attainment in order to identify a causal effect of education on health. The results from these studies are mixed. Lleras-Muney (2005) and Oreopoulos (2006) find a strong link between attained schooling and adult health and mortality, while Clark and Royer (2010) cannot reject the null hypothesis that extra schooling has no significant impact on later-life health.

In this paper we analyze the long-term health and mortality consequences of the introduction of a comprehensive school in Sweden. The comprehensive school, which implied an extension of the number of years of compulsory schooling from 7 or 8 years depending on municipality to a new compulsory national level of 9 years, was implemented by municipalities between 1949 and 1962 as a social experiment. The reform had a sizeable impact on educational attainment in Sweden (Meghir and Palme, 2005; Holmlund, 2007; Spasojevic, 2010). Prior work has shown that labor earnings increased later in life for those exposed to the comprehensive school, in particular for children born in homes with low educated fathers (Meghir and Palme, 2005). We use register data including all Swedes born between 1946 and 1957, which enables us to link assignment to type of school system and health outcomes through different registers. 
We use mortality and hospitalization by cause as well as time of exit from the labor market as outcome measures. The national Cause of Death Register enables us to distinguish between different causes of death - and groups of causes, such as "treatable" and "preventable" to account for the fact that education can affect different aspects of health formation, and thereby death by different cause, differently. The national Patient Register, including information on all hospital stays in Sweden, and the Cancer Register, allow us to do similar analysis on a set of intermediate health measures. Finally, we use time of exit from the labor market as a sub-clinical measure of health. Almost all exits from the labor market before age 65 in Sweden use the disability insurance program to finance their retirement (see e.g. Palme and Svensson, 2004), which requires that health problems prevent the insured individual to do his/her work.

The present study extends the previous literature on the effect of compulsory schooling laws on long-term health outcomes in at least three important ways. First, the staggered adoption of the reform in Sweden's more than 1,000 municipalities (at that time) in a population below 8 million, ensures comparisons of health outcomes of persons in the same birth cohorts and active on the same local labor markets at the same point of time, rather than comparing people across different US states or different birth cohorts in the UK. This ensures that any differences in outcomes are less likely to be the result of differential trends across regional labor markets or birth cohorts. ${ }^{4}$ Second, the detailed diagnosis codes for cause of death and inpatient stays allow us to look deeper into potential mechanisms behind the causal effect of education on long-term health outcomes. The exceptionally large sample size enables to examine heterogeneous reform effects by distinguishing between individuals from different SES backgrounds. Finally, the data allow us to examine a number of intermediate health and health-related outcomes that affect

\footnotetext{
${ }^{4}$ Importantly, Holmlund (2007) offers a number of tests showing that it is not possible to reject the hypothesis that the timing of reform implementation was random with respect to personal characteristics of the affected pupils in the municipality.
} 
individual wellbeing but may not be immediately reflected in mortality data. We draw inferences about the potential effects of extra education on medical care spending later in life, as well as the probability of early retirement.

We find mixed results for the effect of the education reform on mortality up to age 60 . Similarly to Clark and Royer (2010), we find little evidence in favor of large protective effects of education on overall mortality or morbidity. This holds true for both men and women affected by the reform. Our estimates are precise enough to rule out reform treatment effects greater than a $5 \%$ reduction in overall male mortality and a $4 \%$ reduction in female mortality. The main effect of the educational reform seems to be a short-lived gain in expected male years of life that comes from a shift in mortality from ages $45-50$ to ages $50-55$. However, this mortality shift did not significantly affect overall life expectancy. The increase in mortality hazard in the 50-55 age group is large enough to offset the decrease in the 45-50 age group. Importantly, education reform had heterogeneous effects across SES backgrounds. The main mortality effect comes from the group of men born in low SES families.

When we consider mortality by different causes, we find that exposing pupils to more education can have counteracting effects on health outcomes. While some men benefit from reduced overall mortality, others suffer from elevated mortality due to preventable causes of death such as lung cancer and liver cirrhosis. In a competing risks framework, we find that education increases mortality from circulatory diseases and breast cancer for some women, while reducing mortality from preventable causes for others.

We find no consistent evidence that education positively affects intermediate health outcomes as measured by the incidence of hospitalizations and health care costs associated with inpatient episodes. Similarly to mortality, the effects of education on utilization of intermediate 
health inputs appear to vary with age, with lower utilization costs in the mid- to late-40s and higher utilization after the age of 50. However, we find strong positive effects of education on the probability of remaining in the labor force longer, which we argue is most likely driven by perceived better health among more educated individuals.

The rest of the paper proceeds as follows. First, we discuss the relevant literature studying education and mortality and previous work on the effects of the Swedish education reform. In section III we briefly summarize the reform design and the features most relevant to the question at hand. Next, we describe the data and present descriptive evidence of the association between education and health in Sweden. Section VI outlines the empirical strategy. In section VII we discuss our findings and section VIII offers robustness and sensitivity checks. The last section concludes.

\section{Background}

\section{A. Possible mechanisms behind the relation between education and health}

There exists a large literature studying the relationship between education and health. Cutler and Lleras-Muney (2006) and Grossman (2006) offer overviews of the existing hypotheses, studies, and outstanding questions. Cutler and Lleras-Muney (2006) point out three categories of effects that may generate differences in health behavior between groups with different educational attainments: differences in economic resources, time preferences and knowledge.

Economic resources. In most cases more education generates more economic resources. These additional economic resources may be devoted to health care consumption, or general preventive health investments. We expect, however, this channel to be less important in the Swedish setting compared to the US, since Sweden has universal health insurance whereby the 
state covers every resident for the entire cost of health care services. Resources do not necessarily go one way only: increased resources may also increase the demand for goods/activities that reduce health, such as increased alcohol and tobacco consumption, less walking etc.

Time preferences. People who discount future consumption are less likely to both acquire higher education and have good health behavior in order to be able to derive utility from future consumption. This argument has been used for pointing out a possibly spurious correlation between education and health. It is, however, also possible that education may change time preferences, since these may change during different phases of the life course. Using exogenously imposed changes in required educational attainment alleviates the problem somewhat, as individuals are forced to acquire more education regardless of their initial time preferences.

Knowledge. It is possible that more education increases the amount of health information and improves access to information available to the individual. This has implications for health behaviors as well as the patterns of seeking and responding to care. Cutler, Deaton and LlerasMuney (2008) and Glied and Lleras-Muney (2010) suggest that more educated people are more likely to adopt new medical technologies and to seek new medical knowledge and techniques to address treatable conditions more effectively. We directly test this hypothesis by considering the causal effect of education on mortality from treatable conditions.

Grossman (2006) summarizes that education may affect health in two main ways: by improving productive or allocative efficiency. Improved productive efficiency implies that more educated people produce health more efficiently with the same health inputs, for example by possessing and utilizing superior health technologies. If education improves allocative 
efficiency, then conditional on facing the same technologies more educated individuals improve health outcomes by using a more efficient mix of inputs. Due to the universal nature of health care provision and equal access to health technologies in Sweden, we anticipate that in the Swedish setting education reform would work primarily through improvements in allocative efficiency.

\section{B. Studies on the causal effect of education on health}

A large portion of the literature attempting to evaluate the causal effect of extra schooling on health has made use of compulsory schooling reforms for identification. Lleras-Muney (2005) considers the case of the US in the first half of the 20th century, when many states increased the number of years children had to attend school. Her results imply that an extra year of schooling reduces the 10-year mortality rate by over 3 percentage points given a mean mortality rate of ten percent. ${ }^{5}$ She considers cohorts born in the US in the first quarter of the $20^{\text {th }}$ century. Her sample (also studied in Mazumder's 2008 follow-up) differs from the sample studied in this paper in several important ways, and thus the estimated impacts operate on different margins.

The individuals studied by Lleras-Muney were born in the early $20^{\text {th }}$ century and lived during a period of rapid economic growth in the US, the Great Depression, and the Second World War. They faced significantly different institutional environments and were likely born with different health endowments than the average individual alive today. ${ }^{6}$ Second, the compliance rate in the US was much lower than in the UK or in Sweden - Lleras-Muney reports on average only 1 in 20 pupils received one more year of education. It is quite possible that the effects were different for such a small subsample of the population. Last but not least, the age at

\footnotetext{
${ }^{5}$ Mazumder (2008) challenges these results by including state-specific time trends that significantly diminish the estimated coefficients.

${ }^{6}$ For example, due to worse mother's health while in utero.
} 
intervention and treatment "dose" as defined by the number of additional required years of schooling by the US schooling laws are different from the ones required by the European reforms in the 50s and 60s. It is possible that the effect of education on health is non-linear, and that exogenously increasing the compulsory level of education beyond a certain level hits a "flat of the curve" region, where the marginal effect of extra education on future health is negligible. If the effects of extra education vary across age at intervention and the institutional environment, then using different interventions will result in different estimates of the effects (Cutler and Lleras-Muney, 2011).

Oreopolous (2006) and Arendt (2005) also find that increases in minimum schooling laws in England, Ireland, and Denmark respectively, improved the health of the population. They consider somewhat more recent cohorts, but still the youngest individuals in their samples are older than the oldest considered in this study. Moreover, the outcomes they consider are mostly related to self-rated health, while this study uses registry-based health and mortality data.

A recent paper by Royer and Clark (2010) considers the effects of compulsory education laws in Britain in a regression discontinuity design. They report negligible effects of extra schooling on mortality up to age 50 . After age 50 the effects completely disappear.

Spasojevic (2010) analyzes the Swedish comprehensive schooling reform effect on health behaviors and self-rated health using the Swedish Level of Living Survey and finds small increases in the probability that a person reports being in good health attributable to higher education. She uses the reform as an instrumental variable for educational attainment. Unfortunately her analysis is constrained by the small sample size in the survey and she does not control for municipality-specific fixed effects. The survey does not contain information on mortality or health care utilization records for the interviewed individuals. 
All previous large-sample studies (Royer and Clark, 2010; Lleras-Muney, 2005; Oreopoulos, 2006) conduct the analysis on the cohort level, and do not consider important heterogeneities in effects between different subgroups. For example, extra schooling may affect people of low socio-economic backgrounds differently than their better-off peers. Meghir and Palme (2005) found that while education reform increased lifetime labor earnings for men from low SES families, it had a negative effect on the earnings of men from high SES families. Moreover, additional insight can be gained from considering different causes of death as they reveal information about health conditions at the end of life and, indirectly, contain information about the channels through which education affects health. Further, health behaviors are considered to affect some conditions but not others. For example, the incidence of some cancers is considered random in the medical literature, while the incidence of lung cancer is substantially higher among smokers. In this study we test for, and find, heterogeneous effects of the compulsory education reform on individuals coming from different socio-economic backgrounds. In addition to an average treatment effect, we offer estimates that can be interpreted as a treatment effect on the treated. We also differentiate between different causes of death and offer additional evidence on intermediate health outcomes from hospitalization records. 


\section{II. $\quad$ C. Studies on the comprehensive school reform in Sweden}

Meghir and Palme (2005) and Holmlund (2007) study the effect of the comprehensive school reform on educational attainments. ${ }^{7}$ Meghir and Palme's (2005) estimates for their entire sample are 0.252 additional years for males and 0.339 years for females; for low SES persons the estimates are 0.3 extra years for males and 0.512 for females. Holmlund has estimates in the range 0.21-0.61 additional years of schooling for men and 0.13-0.44 for women.

\section{The Comprehensive School Reform}

\section{III.A. The Swedish school system before and after the reform}

Prior to the implementation of the comprehensive school reform, pupils attended a common basic compulsory school (folkskolan) until grade six. After the sixth grade pupils were selected to either continue one or, in mainly urban areas, two years in the basic compulsory school, or to attend the three year junior secondary school (realskolan). The selection of pupils into the two different school tracks was based on their past performance, measured by grades. The pre-reform compulsory school was in most cases administered at the municipality level. The junior secondary school was a prerequisite for the subsequent upper secondary school, which was itself required for higher education.

\footnotetext{
${ }^{7}$ Holmlund (2007) does not have individual treatment status and imputes it from municipality of residence in 1960. She uses OLS and IV techniques to account for attenuation bias caused by measurement errors
} 
In 1948 a parliamentary school committee proposed a school reform that implemented a new nine-year compulsory comprehensive school. ${ }^{8}$ The comprehensive school reform had three main elements:

1. An extension of the number of years of compulsory schooling to 9 years in the entire country.

2. Abolition of early selection. Although pupils in the comprehensive schools were able to choose between three tracks after the sixth grade - one track including vocational training, a general track, and an academic level preparing for later upper secondary school - they were kept in common schools and classes until the ninth grade.

3. Introduction of a national curriculum. The pre-reform compulsory schools were administrated by municipalities and the pre-reform curriculum varied between municipalities.

\section{III.B. The social experiment}

The social experiment with the new comprehensive nine-year compulsory school started during an assessment period between 1949 and 1962, when the final curriculum was decided. ${ }^{9}$ The proposed new school system, as described above, was introduced in municipalities or parts of city communities, which in 1952 numbered 1,055 (including 18 city communities). Figure 1 shows the take up rate of the experiment by cohort. It is evident from Figure 1 that the cohorts included in our empirical analysis, born between 1945 and 1957, cover the entire period of implementation of the comprehensive school. In 1962 it was decided that the new comprehensive

\footnotetext{
8 The school reform and its development are described in Meghir and Palme (2003), Meghir and Palme (2005), and Holmlund (2007). For more detailed reference on the reform, see Marklund (1981).

${ }^{9}$ The official evaluation was mainly of administrative nature. Details on this evaluation are also described in Marklund (1981).
} 
school would become the standard education in Sweden. The last class that graduated from the old schooling system did so in $1970 .^{10}$

Figure 1: Percentage share of birth cohort assigned to the post reform school system.

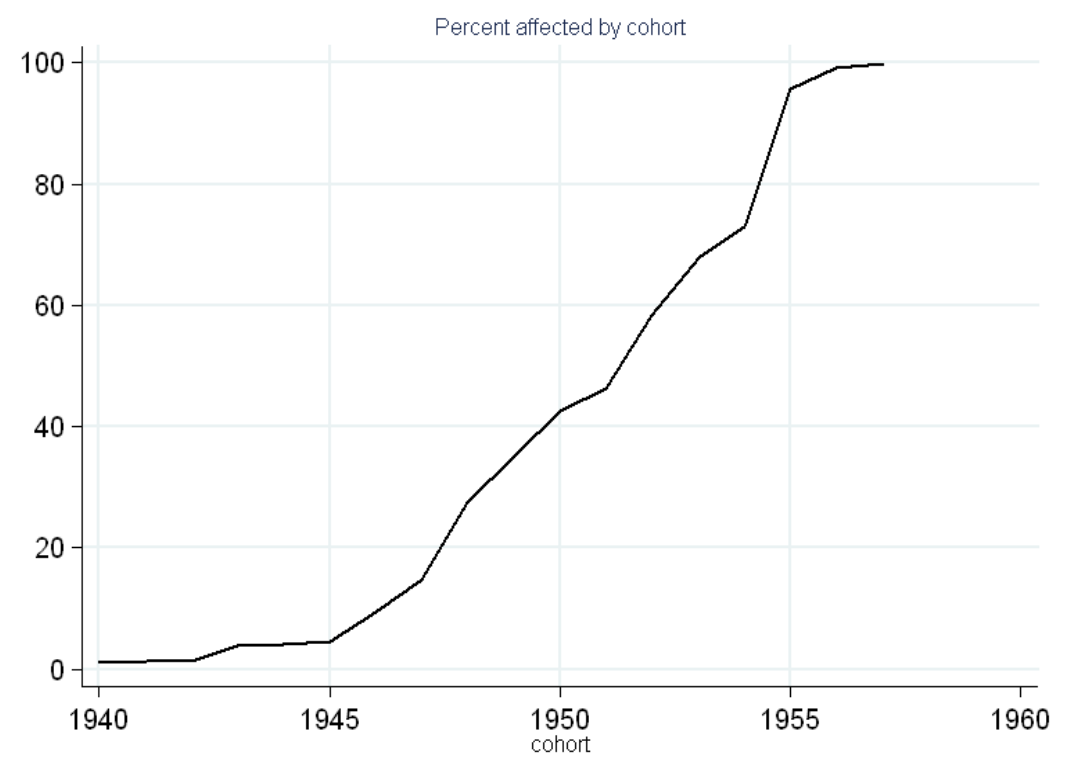

The selection of municipalities was not based on random assignment. However, the decision to select the areas was based on an attempt to choose areas that were representative for the entire country, both in terms of demographics as well as geographically. At first the National Board of Education contacted the municipalities, or sometimes they themselves applied to participate. From this pool of applicants a "representative" sample of municipalities was chosen. Municipalities could elect to implement the comprehensive school starting with first or fifth grade cohorts. Once the grade of implementation was fixed, all individuals from the cohort immediately affected and all subsequent cohorts went to comprehensive school. The older cohorts continued in the per-reform school.

\footnotetext{
${ }^{10}$ Table A1 in the appendix shows the number of observations in each birth cohort and the proportion assigned to the reform.
} 


\section{Data and Measurement}

Our sample is obtained from the Swedish population censuses. It consists of all individuals born in Sweden between 1946 and 1957. These cohorts consist of 1,461,785 individuals, of whom 746,201 are males and are 715,584 females. Information on reform treatment is available for 714,694 women and 745,330 men. We also use information on the parents of these individuals. Identities of the parents were obtained from the multi-generation register provided by Statistics Sweden. ${ }^{11}$ Data on these two generations are subsequently obtained from various national registers that can be linked through unique personal identification numbers.

The reform assignment variable is obtained in two steps. First, we use the name of the church parish of birth in order to obtain the municipality code according to the 1953 Swedish municipality division. Second, based on the year and municipality of birth, we use an algorithm based on historical evidence on reform implementation in each municipality provided by Helena Holmlund and described in Holmlund (2007) to assign reform status to each individual in the sample.

Data on educational attainments is obtained from the 1990 Swedish education register, containing detailed information on the highest education obtained by each individual in 1990 . Data on educational attainment of the parent generation is obtained from the 1970 census. Since this census only contains information on all individuals of age 60 and younger, we are missing information on all parents who were older, deceased or had permanently emigrated by 1970 . We code family socio-economic status based on the father's highest level of education. If the father

\footnotetext{
${ }^{11}$ Statistics Sweden (2003) Flergenerationregistret 2002. En beskrivning av innehåll och kvalitet. Statistics Sweden. Avdelning för Befolknings och Välfärdsstatistik.
} 
had any education beyond the basic compulsory level, we code the child as coming from a high socio-economic status family. If the father had only the minimum required level of education (7 years), the child is coded as low SES.

Data on date of death is obtained from the national Cause of death register (Socialstyrelsen, 2009a). This register contains date and three digit ICD 9 codes for the main underlying cause of death for all Swedish citizens. Mortality data for this sample are available between 1985 and 2005. Thus we can only estimate effects on mortality between the ages of 28 and 60. While this puts age restrictions on the conclusions we draw using this sample, the period does cover the most productive periods of a person's life. We believe that the findings are economically meaningful even though we do not observe mortality among older adults and the elderly.

Data on all hospital admissions between 1987 and 2005 was collected from the Swedish National Patient Register (Socialstyrelsen, 2009b) This register also contains administrative information such as date of admission, number of days in hospital care as well as discharge diagnoses classified according to the 9th and 10th versions of International Classification of Diseases (ICD). The National Patient Register records a hospital admission only if it included an overnight hospital stay. Emergency room visits and shorter-term (less than 24 hours) inpatient stays are not recorded.

The Patient Register does not keep record of the costs associated with individual hospitalizations. To gain some insight into potential differences in costs of care between individuals who went through the two different education systems, we use the Centers for Medicare and Medicaid Services Hierarchical Condition Categories (CMS-HCC) aggregation into risk categories based on average costs of hospitalizations for aggregated categories of ICD9 
codes. The purpose of the CMS-HCC software is to adjust Medicare capitation payments to Medicare Advantage health plans for the health expenditure risks of their enrollees. The software uses ICD9 diagnosis codes from hospitalizations during the year as well as information on gender and age to develop an individual risk score that reflects expected costs for the individual in the following year. Lower risk scores mean lower expected medical costs. A thorough explanation of how the software works can be found in Pope et al (2011). ${ }^{12}$ For consistency, the 2011 version of the CMS-HCC software was used for all years of hospitalization data (19862005). Since the identification of the reform effect comes from relative differences between individuals in the same birth cohorts, and all people from the same cohort are evaluated using the same CMS-HCC scoring technique, the CMS-HCC risk scores are a convenient tool to evaluate relative differences in expected health care costs even though they are based on average expenditures in the US rather than in Sweden.

For the analysis on exit from the labor market we use information from the LISA register on taxed income from labor. Income from labor includes income from the unemployment insurance and the sick-pay insurance (temporary disability insurance) program. This means that those who do not have any insurance income are not in the labor force. Jönsson, Palme and Svensson (2011) has shown that almost all who leave the labor force before age 60 receive benefits from the disability insurance program and for this age group long term health problems preventing the insured individual to do his or her regular work has been the eligibility criterion for the program. ${ }^{13}$ If a person does not have any income from labor for two consecutive years he or she is defined as having exited from the labor market at the first year of no income from labor.

\footnotetext{
12 https://www.cms.gov/MedicareAdvtgSpecRateStats/downloads/Evaluation_Risk_Adj_Model_2011.pdf

13 The right to disability insurance for labor market reasons in the age group 60-65 was abolished in 1991(see e.g. Jönsson, Palme and Svensson, 2011).
} 
Table 1 below reports the basic characteristics of the individuals born between 1946 and 1957 and educated in the two systems. Swedes who went through the old schooling system are older as the reform was rolled out nationally over time. Those who went through the post-reform school system obtained on average half a year more of education. The difference in education levels is, as expected, most striking at the lowest level. We see the old compulsory schooling level attained by only $2 \%$ of the treated vs. $16.6 \%$ of the untreated individuals. The second largest difference between the two groups is in attaining education level 2, the new compulsory level. Swedes affected by the reform are $6.5 \%$ more likely to attain that education level compared to those who went through the old schooling system. 
Table 1: Summary statistics of main outcomes and controls [standard deviations in square brackets].

\begin{tabular}{|c|c|c|c|c|}
\hline \multirow[b]{2}{*}{ Variable } & \multicolumn{2}{|c|}{ Pre reform } & \multicolumn{2}{|c|}{ Post reform } \\
\hline & $\begin{array}{l}\text { Number of } \\
\text { observations }\end{array}$ & Means & $\begin{array}{l}\text { Number of } \\
\text { observations }\end{array}$ & Means \\
\hline Female & 639,773 & 0.49 & 819,686 & 0.487 \\
\hline$N$ children & 639,773 & $\begin{array}{r}1.9 \\
{[1,246]}\end{array}$ & 819,686 & $\begin{array}{c}1.9 \\
{[1,262]}\end{array}$ \\
\hline Years of education & 591,951 & $\begin{array}{c}11.2 \\
{[3.108]}\end{array}$ & 779,172 & $\begin{array}{c}11.8 \\
{[2.828]}\end{array}$ \\
\hline Died by 2005 & 639,773 & 0.046 & 819,686 & 0.033 \\
\hline Hospitalized $1986-2005^{14}$ & 639,773 & 0.58 & 819,686 & 0.55 \\
\hline Retired by 2006 & 729,757 & 0.518 & 722,558 & 0.509 \\
\hline Average age in 2006 & 639,773 & $\begin{array}{c}57 \\
{[3.782]}\end{array}$ & 819,686 & $\begin{array}{c}52 \\
{[3.333]}\end{array}$ \\
\hline Education level1 (old compulsory) & 591,951 & 0.166 & 779,172 & 0.0219 \\
\hline Education level2 (new compulsory) & 591,951 & 0.0991 & 779,172 & 0.1645 \\
\hline Education level3 (vocational) & 591,951 & 0.4550 & 779,172 & 0.4821 \\
\hline Education level4 (high school only)) & 591,951 & 0.0401 & 779,172 & 0.0549 \\
\hline Education level5 (college) & 591,951 & 0.2304 & 779,172 & 0.2660 \\
\hline Education level6 (PhD) & 591,951 & 0.0087 & 779,172 & 0.0103 \\
\hline
\end{tabular}

\section{The Association between Education and Health in Sweden}

Our first approach to the data is to analyze the correlations between education and mortality in the Swedish population. Table 2A shows the hazard rates estimated from Cox proportional hazard regressions broken down by gender and into mortality by cause. Mortality causes are grouped into five exclusive categories: cancer, circulatory, preventable, treatable, and others. Appendix table A2 lists the ICD9 diagnoses that enter in each group. In Appendix table A3 we show the distribution of deaths by difference cause in the treated and control populations.

Hazard rates that are lower than unity indicate a protective effect; those above unity imply an increase in the hazard associated with a unit change in the variable. The confidence interval is shown in brackets. An extra year of education is associated with a lower overall mortality risk up to age sixty by $10.5 \%$ among men and by $9 \%$ among women. This is within the

\footnotetext{
${ }^{14}$ Hospitalizations excluding hospitalizations for delivery and related obstetrics procedures
} 
range implied by US estimates reported by Lleras-Muney and Cutler (2006), who find a 1.8 percentage point reduction associated with an extra year of education in the 5-year mortality rate among adults aged 25 and over. ${ }^{15}$ These are large significant gains in life expectancy associated with more education.

Table 2A: The relationship between years of education and mortality from different causes. Cox stratified proportional hazard models. 95 percent confidence intervals in parentheses.

\begin{tabular}{|c|c|c|c|c|c|c|}
\hline Men & (1) & (2) & (3) & (4) & (5) & (6) \\
\hline & Any cause & Cancer & Circulatory & Preventable 16 & Treatable & Other \\
\hline Years of & $0.894^{*}$ & $0.939^{*}$ & $0.884^{*}$ & $0.813^{*}$ & $0.899^{*}$ & $0.885^{*}$ \\
\hline Schooling & $\begin{array}{l}(0.881- \\
0.906)\end{array}$ & $\begin{array}{l}(0.916- \\
0.962)\end{array}$ & $\begin{array}{l}(0.867- \\
0.902)\end{array}$ & $\begin{array}{l}(0.782- \\
0.845)\end{array}$ & $\begin{array}{l}(0.868- \\
0.931)\end{array}$ & $\begin{array}{l}(0.868- \\
0.902)\end{array}$ \\
\hline Sample size & 691,756 & 691,756 & 691,756 & 691,756 & 691,756 & 691,756 \\
\hline Women & (1) & (2) & (3) & (4) & (5) & (6) \\
\hline Age & Any cause & Cancer & Circulatory & Preventable & Treatable & Other \\
\hline Years of & $0.910^{*}$ & $0.955^{\star}$ & $0.842^{*}$ & $0.874^{*}$ & $0.861^{*}$ & $0.900^{*}$ \\
\hline Schooling & $\begin{array}{l}(0.897- \\
0.923)\end{array}$ & $\begin{array}{l}(0.941- \\
0.969)\end{array}$ & $\begin{array}{l}(0.815- \\
0.869)\end{array}$ & $\begin{array}{l}(0.847- \\
0.901)\end{array}$ & $\begin{array}{l}(0.818- \\
0.906)\end{array}$ & $\begin{array}{l}(0.870- \\
0.930)\end{array}$ \\
\hline Sample size & 680,416 & 680,416 & 680,416 & 680,416 & 680,416 & 680,416 \\
\hline \multicolumn{7}{|c|}{ Robust $95 \%$ confidence intervals in parentheses;+ significant at $10 \% ;{ }^{* *}$ significant at $5 \% ;{ }^{*}$ significant at $1 \%$} \\
\hline
\end{tabular}

Interesting patterns emerge when we break down mortality by the main causes - cancers, circulatory disease, and potentially treatable and avoidable mortality. Consistent with the view that the risk of getting cancer diseases are less affected by lifestyles and health behaviors, increases in education are associated with the smallest gains in cancer-related mortality. It is

\footnotetext{
${ }^{15}$ In a robustness check we defined the 5 -year mortality rate by municipality and birth cohort as defined by Cutler and Lleras-Muney (2006) and estimated OLS coefficients of the effects of an extra year of education on the 5-year mortality rate controlling for municipality of birth and cohort fixed effects. We found estimates very similar to the ones reported for the US - around 4 percent decrease in the 5-year rate for men and 3.7 percent decrease for women. ${ }^{16}$ Includes lung cancers and liver cirrhosis only
} 
important to stress here that cancer mortality depends both on the incidence and the treatment of cancer, thus even if we expect completely random incidence, disparities would emerge if more educated individuals receive better or more timely care.

The strongest gains due to education are in preventable mortality for men. This cause of death category groups lung cancer and liver cirrhosis, which are strongly associated with smoking and drinking, respectively. These types of mortality are most strongly affected by health behaviors and lifestyle, suggesting that health behaviors are a major channel through which education affects health. The strongest effect of education for women is on circulatory disease mortality. Across all categories, men benefit more from an extra year of education than women do.

Education may have a non-linear effect on mortality. In Appendix Table A4 we include dummies for education levels - vocational, secondary school, college/university, and PhD instead of a linear control for years of education. The omitted category is compulsory education; hence the coefficient estimates are interpretable as average mortality within the group as compared to the omitted (lowest) level of education. The protective effect of education increases as individuals acquire more education. Across all age groups, increasing educational achievement is associated with a decrease in mortality risk. Based on the correlation coefficients, more education is always associated with better health, even at levels significantly above the average educational achievement $(\mathrm{PhD})$.

In table $2 \mathrm{~B}$ we show the relationship between education and the probability of being hospitalized. The outcome is a binary variable equal to one if the person was hospitalized overnight for any cause at any time during the period 1987-2005. We run linear probability models. Even if we were to take education as exogenous, the probability of hospitalization 
depends on two potentially conflicting channels. First, worsening underlying health would increase the incidence of hospitalizations. This implies that more educated individuals would be hospitalized less often. However, hospitalization is also a means of health investment. Higher educated individuals may have higher returns from such investments. This implies that more educated people would be more likely to be hospitalized for planned treatments. In addition, higher educated individuals may have lower discount rates and thus invest more anyway, further increasing hospitalizations. As it turns out (Table 2B) hospitalizations are negatively associated to increases in education. An extra year of schooling decreases the probability of hospitalization by 1.4 percentage points among men and by 0.8 percentage points among women. We emphasize that cancer hospitalizations do not appear to be significantly affected by education; however cancer mortality is lower among the better educated. This suggests that one of the channels through which education lowers mortality is by improving survival chances post-diagnosis.

Table 2B: The effects of education on hospitalizations. OLS estimates controlling for municipality and birth cohort effects. 95 percent confidence intervals in parentheses.

\begin{tabular}{|c|c|c|c|c|c|}
\hline Men & (1) & (2) & (3) & (4) & (5) \\
\hline & Any cause & Cancer & Circulatory & Preventable & Treatable \\
\hline $\begin{array}{l}\text { Years of } \\
\text { schooling }\end{array}$ & $\begin{array}{l}-0.014^{*} \\
(-0.015- \\
0.013)\end{array}$ & $\begin{array}{l}-0.00015+ \\
(-0.00032- \\
0.00001)\end{array}$ & $\begin{array}{l}-0.00501^{*} \\
(-0.00539- \\
0.00463)\end{array}$ & $\begin{array}{l}-0.00031^{*} \\
(-0.00037- \\
0.00026)\end{array}$ & $\begin{array}{l}-0.00610^{*} \\
(-0.00656- \\
0.00564)\end{array}$ \\
\hline Sample size & 691756 & 691756 & 691756 & 691756 & 691756 \\
\hline \multirow[t]{2}{*}{ Women } & (1) & (2) & (3) & (4) & (5) \\
\hline & Any cause & Cancer & Circulatory & Preventable & Treatable \\
\hline $\begin{array}{l}\text { Years of } \\
\text { schooling }\end{array}$ & $\begin{array}{l}-0.008^{*} \\
(-0.009-0.007)\end{array}$ & $\begin{array}{l}0.00014 \\
(-0.00005 \\
0.00033)\end{array}$ & $\begin{array}{l}-0.00417^{*} \\
(-0.00460- \\
0.00373)\end{array}$ & $\begin{array}{l}-0.00027^{*} \\
(-0.00031- \\
0.00023)\end{array}$ & $\begin{array}{l}-0.00674^{*} \\
(-0.00725- \\
0.00622)\end{array}$ \\
\hline Sample size & 680416 & 680416 & 680416 & 680416 & 680416 \\
\hline
\end{tabular}


Table 3 shows the estimated hazard ratios from a Cox proportional hazard model for retirement using years of schooling and dummy variables for cohort of birth as independent variables. The results reveal a very strong association between education and the timing of retirement: every year of additional education is associated with an about 9 percent decrease in the probability of exiting from the labor force for both males and females. As a sensitivity analysis, we have repeated these estimates using different thresholds for labor earnings and the results are robust to these checks.

Table 3: Hazard ratios from Cox proportional hazard models of the association between years of schooling and retirement. 95 percent confidence intervals in parentheses.

\begin{tabular}{lcc}
\hline & Males & Females \\
\hline Years of schooling & $0.9103^{*}$ & $0.9101^{*}$ \\
& $(0.8983-0.9224)$ & $(0.9072-0.9129)$ \\
Sample size & 755,634 & 742,785 \\
\hline + significant at $10 \% ;{ }^{* *}$ significant at $5 \%{ }^{*}{ }^{*}$ significant at $1 \%$ & \\
\hline
\end{tabular}

\section{Identification and Empirical Strategy}

We use two main types of outcomes. When we consider mortality and retirement, we use time to death (retirement) as the outcome variable. For hospitalizations we use an indicator variable for a hospital stay between 1987 and 2005 as outcome. Throughout, we present results for males and females separately, since they might follow very different underlying health processes. We also present results for people with low- and highly-educated fathers separately. The reason for this division is that, as shown in Meghir and Palme (2005), the reform had much stronger effects on educational attainments and labor earnings in the group from low educated families. To the extent that education has a causal effect of health outcomes we would thus expect to be stronger in this group. 
We use the same identification strategy for the effect of the reform for both types of outcomes. If the reform would have been randomly distributed among Sweden's 1,000 or so municipalities we could have simply compared the outcomes in the treated and non-treated municipalities conditional on year of birth. However, as we described in Section III, this was not the case. Therefore, we will control for both year and municipality of birth. We start with the following latent variable specification:

$y_{i, m, t}^{*}=\alpha+\beta_{1} R_{i, m, t}+\gamma_{1}^{\prime} T_{i}+\gamma_{2}^{\prime} M_{i}+\varepsilon_{i, m . t}$,

where $i, m$ and $t$ are sub-indices for individual, municipality and birth cohort, respectively; $y^{*}$ is a latent variable for health status; $T$ is a vector of dummy variables for year of birth; $M$ is a corresponding vector of dummy variables for municipality of birth; finally, $\varepsilon$ is a individual random disturbance.

Given the additive form above, the key identifying assumption is that the distribution $f(\cdot)$ of does not depend on the assignment to treatment, conditional on cohort and municipality, i.e. $f\left(\varepsilon_{i, m, t} \mid R_{i, m, t}, T_{i}, M_{i}\right)=f\left(\varepsilon_{i, m, t} \mid T_{i}, M_{i}\right)$, where $f(\cdot \mid \cdot)$ denotes the conditional density. In practice we impose the stronger assumption that the distribution of is independent of all right hand side variables.

It is important to note that the reform assignment in this analysis depends on the municipality of birth, rather than the municipality of schooling. On the one hand, this means that the estimates are of the "intention-to-treat" type. On the other hand we avoid selection issues coming from differential endogenous mobility. ${ }^{17}$

\footnotetext{
${ }^{17}$ However, selective mobility is unlikely, as shown in Meghir and Palme (2005).
} 
For the binomial outcomes (hospitalizations) we use linear probability models for estimating the reform effect, i.e., $\operatorname{Pr}\left(y_{i, m, t}^{*}>0 \mid R_{i, m, t}, T_{i}, M_{i}\right)=\alpha+\beta_{1} R_{i, m, t}+\gamma_{1}{ }^{\prime} T_{i}+\gamma_{2}{ }^{\prime} M_{i}$, which is straightforwardly estimated using GLS. The reason for using a linear probability model, rather than e.g. logit and probit, which restrict the probabilities in the $[0,1]$ interval and relax the linearity assumption, is computational convenience, since all models include about 1,000 municipality indicator variables in addition to the 12 year of birth indicators. For relatively small treatment effects, when both approaches have been used in a similar context, the results are almost identical. $^{18}$

For the time to death (retirement) outcomes we use Cox proportional hazard models, i.e.,

$I_{1, i, m, t}\left(r \mid R_{i, m, t}, T_{i}, M_{i}\right)=I_{0}(r) \exp \left\{\alpha+\beta_{1} R_{i, m, t}+\gamma_{1}^{\prime} T_{i}+\gamma_{2}{ }^{\prime} M_{i}\right\}$,

where $r$ is exposure time and $I_{0}(r)$ is the baseline hazard. This model is semi-parametric in the sense that no functional form assumption is imposed on the base line hazard.

We estimate competing risk models for several different causes of death. We maintain the Cox proportional hazard framework and treat all other causes of death as right censored from the day they pass away. This procedure gives consistent estimates for each cause of death under the assumption of independent latent risk of death from different causes, i.e., other causes of death can be treated as random right censoring.

\section{Results}

VII.A. The effect of the comprehensive school reform on educational attainments and earnings later in life

\footnotetext{
${ }^{18}$ See for example Meghir, Palme and Schnabel (2011).
} 
Before we turn to the analysis of educational reform on mortality, we present evidence on the effect of schooling reform on the years of completed schooling among the affected cohorts. ${ }^{19}$ In Table 4 we first report the estimated reform effect on all individuals, and then we show two additional sets of results - the effect of the reform by paternal SES and by gender. Based on the findings of previous research and the targeted population group, we expect children whose parents had lower SES to benefit more from the reform: this is indeed the case as seen in Table 4. The average effect of the reform was an increase in attained years of education of 0.14 , which is a little over one and a half months. Both high and low SES background children are affected by the reform, but the magnitudes of the effects are very different. High SES children's educational attainment increases by $6 \%$ of a school year, while low SES children's education increases by $21 \%$, or two and a half calendar months.

Table 4: The effect of the educational reform on years of completed schooling.

\begin{tabular}{llll} 
& $(1)$ & $(2)$ & $(3)$ \\
& All & Low Father's education & High father's education \\
\hline Reform & $0.144^{*}$ & $0.213^{*}$ & $0.062^{* *}$ \\
& $(0.021)$ & $(0.016)$ & $(0.024)$ \\
Sample size & $1,246,937$ & 560,587 & 313,150 \\
$R^{2}$ & 0.032 & 0.020 & 0.017 \\
& & & \\
Men & & & \\
Reform & $0.176^{*}$ & $0.278^{*}$ & $0.072+$ \\
& $(0.025)$ & $(0.021)$ & $(0.037)$ \\
Sample size & 627,886 & 285,145 & 159,497 \\
$R^{2}$ & 0.040 & 0.027 & 0.024 \\
& & & \\
Women & & & \\
Reform & $0.113^{*}$ & $0.144^{*}$ & $0.053+$ \\
& $(0.028)$ & $(0.021)$ & $(0.028)$ \\
Sample size & 619,051 & 275,442 & 153,653 \\
$R^{2}$ & 0.031 & 0.020 & 0.019 \\
\hline
\end{tabular}

Robust $95 \%$ conf. intervals in parentheses;+ significant at 10\%; ** significant at 5\%; * significant at $1 \%$

\footnotetext{
${ }^{19}$ Extensive analyses and discussions of the nature and the validity of the reform as a social experiment is available in Holmlund (2007) and Meghir and Palme (2005).
} 
Breaking down the effect by SES, we see that the group that benefited most from the reform was boys coming from low educated families. Among members of this group the reform resulted in an increase of one third of a school year on average. The corresponding change for girls is a month less. Overall, the reform affected boys more strongly than girls. High SES boys and girls experience small gains in total years of schooling, the coefficients being marginally significant in both groups and economically small. The reform effect on children coming from low SES families is about three times as large. Thus we expect the bulk of the reform effect to be demonstrated among individuals with low SES background, and in particular low SES males. Finally, when considering levels of attainment it becomes apparent that the main effect for men is driven by changes at the lower end of education only. ${ }^{20}$

The education effects obtained here are similar in magnitude to those reported by Meghir and Palme (2005) who study a random subset of the population of around 12,000 individuals born in 1948 and 1953 and by Holmlund (2008) who uses a 35\% random sample of the population. Compared to Meghir and Palme (2005) who use survey responses to assign reform status to individuals, here we probably have a noisier measure of reform participation, which attenuates our estimates somewhat.

The earlier literature has pointed out that improved economic resources are a possible mechanism underlying a causal relation between education and health. To investigate the potential importance of this channel, Table 5 reports the results on the effect of the education reform on labor earnings later in life. For each individual we have included data on earnings from labor from tax returns between 1990 and 2006. We use the same specification as for the

\footnotetext{
${ }^{20}$ We have left out more details for the sake of brevity.
} 
differences-in-differences regressions of the effects on final educational attainments reported in Table 4, but here we also add fixed effects for each year of earnings.

The results in Table 5 reveal an interesting pattern. The effect of the reform in the population including both men and women is quite small and only significant in the group originating from low SES homes. The effect is driven by a $6.7 \%$ effect for men of low SES background. For women the reform effect is completely insignificant. It is notable that the results are somewhat different to those obtained in Meghir and Palme (2005). They are, however, obtained on a different population. Meghir and Palme (2005) use a random sample restricted to those born in 1948 and 1953 and a different earnings panel 1985-1996.

Table 5: The effect of the educational reform on log earnings from labor between 1990 and 2006. Robust standard errors in parentheses.

\begin{tabular}{llll}
\hline & $(1)$ & $(2)$ & $(3)$ \\
& All & Low father's education & High Father's education \\
\hline Reform & 0.022 & $0.025+$ & 0.002 \\
& $(0.016)$ & $(0.014)$ & $(0.018)$ \\
Sample size & $23,499,560$ & $10,287,885$ & $5,687,767$ \\
$R^{2}$ & 0.022 & 0.007 & 0.006 \\
& & & \\
Men & & & \\
Reform & $0.053^{*}$ & $0.067^{*}$ & 0.016 \\
& $(0.019)$ & $(0.021)$ & $(0.030)$ \\
Sample size & $11,887,636$ & $5,248,169$ & $2,906,355$ \\
$R^{2}$ & 0.025 & 0.010 & 0.010 \\
& & & \\
Women & & & -0.015 \\
Reform & -0.008 & -0.020 & $(0.025)$ \\
& $(0.019)$ & $(0.020)$ & $2,781,412$ \\
Sample size & $11,611,924$ & $5,039,716$ & 0.006 \\
$R^{2}$ & 0.021 & 0.008 & \\
\hline
\end{tabular}

Note: + significant at $10 \% ;{ }^{* *}$ significant at $5 \% ;{ }^{*}$ significant at $1 \%$

VII. B. The effects of the reform on mortality

Table 6 reports the estimates from model (2) with mortality from any cause as the dependent variable for age groups 40-49 and 50-60, respectively, as well as for the entire 
population. To address concerns about differential trends across early and late-reform adopters, we show results from two sets of specifications: one is including and one is excluding a linear time trend interacted with each year of reform implementation. The upper panel shows the results for men and the lower for women. Tables $6 \mathrm{~A}$ and $6 \mathrm{~B}$ show the results for those originating from a home with low and highly educated fathers separately. The reason for showing the results for these groups separately is that the low SES background subset drives the increase in educational attainments and is thus more likely to represent the treated group. The reform did not significantly affect the quantity of education in the group with well-educated fathers.

Table 6 shows that there is a marginally significant decrease in mortality as a result of the reform for males in the 40-50 age group in the specification including heterogeneous time trends. An interpretation of the marginally significant increase in mortality in the age group 50-60 is that those experiencing a delayed mortality in the younger age group "catch up" in older ages. The lower confidence interval bounds tell us that we can exclude decreases in mortality larger than 5 percent for all men and larger than 6.8 percent for low SES men. As expected, these effects are stronger in the low SES group. Table 6 also shows that the results for females are insignificant throughout.

The survival gains from reform treatment are isolated in the 40-50 age group and are quickly reversed in the next decade. A simple back-of-the-envelope calculation using the point estimates from Table 6 and the 10-year population-wide mortality rates reveals the following. The crude mortality rate in the male population aged $40-50$ is 2.22 percent, so that a forty-yearold male can expect to live 9 years and 9.3 months in the next 10 years. The numbers are very similar in the 50-60 age group category. Comparing reform-treated and untreated men we find 
that on average a reform-treated 40 -year-old man can expect to live about 4 more days (5\% of 2.6 months) in the next 10 years than a man who went through the old schooling system. However, conditional on reaching the age of 50, the effect reverses and reform-treated men can expect to live on average about 4 days less in the next decade than their untreated peers. These estimates double in magnitude but maintain their general pattern in the group of low SES men. 
Table 6: Cox proportional hazard model estimates of the effect of the educational reform on mortality.

\begin{tabular}{|c|c|c|c|c|c|c|}
\hline $\begin{array}{l}\text { Men } \\
\text { Age } \\
\text { Reform }\end{array}$ & \multicolumn{2}{|c|}{ 40-50 age group } & \multicolumn{2}{|c|}{ 50-60 age group } & \multicolumn{2}{|c|}{ aggregate } \\
\hline Reform & $\begin{array}{c}0.966 \\
(0.918- \\
1.016)\end{array}$ & $\begin{array}{c}0.945+ \\
(0.889- \\
1.005)\end{array}$ & $\begin{array}{c}1.083^{* *} \\
(1.015- \\
1.157)\end{array}$ & $\begin{array}{c}1.058 \\
(0.972- \\
1.152)\end{array}$ & $\begin{array}{c}1.001 \\
(0.967- \\
1.035)\end{array}$ & $\begin{array}{c}0.989 \\
(0.950- \\
1.030)\end{array}$ \\
\hline Linear trend & & $\mathrm{x}$ & & $\mathrm{x}$ & & $\mathrm{x}$ \\
\hline Deaths & 16,374 & 16,374 & 12,250 & 12,250 & 35,195 & 35,195 \\
\hline Sample size & 738,469 & 738,469 & 552,131 & 552,131 & 745,185 & 745,185 \\
\hline \multicolumn{7}{|l|}{ Women } \\
\hline Age & \multicolumn{2}{|c|}{ 40-50 age group } & \multicolumn{2}{|c|}{ 50-60 age group } & \multicolumn{2}{|c|}{ aggregate } \\
\hline Reform & $\begin{array}{c}1.056 \\
(0.975- \\
1.143)\end{array}$ & $\begin{array}{c}1.061 \\
(0.974- \\
1.156)\end{array}$ & $\begin{array}{c}0.946 \\
(0.867- \\
1.031)\end{array}$ & $\begin{array}{c}0.927 \\
(0.834- \\
1.030)\end{array}$ & $\begin{array}{c}1.004 \\
(0.955- \\
1.055)\end{array}$ & $\begin{array}{c}1.010 \\
(0.957- \\
1.066)\end{array}$ \\
\hline Linear trend & & $\mathrm{x}$ & & $x$ & & x \\
\hline Deaths & 10,097 & 10,097 & 7,947 & 7,947 & 21,345 & 21,345 \\
\hline Sample size & 711,130 & 711,130 & 536,215 & 536,215 & 714,549 & 714,549 \\
\hline \multicolumn{7}{|c|}{ Table 6A: Low SES background subsample } \\
\hline \multicolumn{6}{|c|}{ Men } & aggregate \\
\hline Reform & $\begin{array}{c}0.932 \\
(0.856- \\
1.014)\end{array}$ & $\begin{array}{c}0.906^{\star *} \\
(0.824-0.997)\end{array}$ & $\begin{array}{c}1.107+ \\
(0.995- \\
1.233)\end{array}$ & $\begin{array}{c}1.091 \\
(0.949- \\
1.254)\end{array}$ & $\begin{array}{c}0.996 \\
(0.938- \\
1.058)\end{array}$ & $\begin{array}{c}0.994 \\
(0.932- \\
1.060)\end{array}$ \\
\hline Linear trend & & $\mathrm{x}$ & & $\mathrm{x}$ & & $\mathrm{x}$ \\
\hline Deaths & 6,712 & 6,712 & 4,876 & 4,876 & 13,722 & 13,722 \\
\hline $\begin{array}{l}\text { Sample } \\
\text { size }\end{array}$ & 321,158 & 321,158 & 314,452 & 314,452 & 323,321 & 323,321 \\
\hline \multicolumn{7}{|l|}{ Women } \\
\hline Age & \multicolumn{2}{|c|}{ 40-50 age group } & \multicolumn{2}{|c|}{ 50-60 age group } & \multicolumn{2}{|c|}{ aggregate } \\
\hline Reform & $\begin{array}{c}1.083 \\
(0.967- \\
1.212)\end{array}$ & $\begin{array}{c}1.114+ \\
(0.989-1.256)\end{array}$ & $\begin{array}{c}0.926 \\
(0.807- \\
1.063)\end{array}$ & $\begin{array}{c}0.914 \\
(0.769- \\
1.086)\end{array}$ & $\begin{array}{c}1.034 \\
(0.956- \\
1.120)\end{array}$ & $\begin{array}{c}1.058 \\
(0.968- \\
1.156)\end{array}$ \\
\hline Linear trend & & $x$ & & $\mathrm{x}$ & & $\mathrm{x}$ \\
\hline Deaths & 4,226 & 4,226 & 3,109 & 3,109 & 8,828 & 8,828 \\
\hline Sample size & 305,891 & 305,891 & 301,775 & 301,775 & 306,926 & 306,926 \\
\hline
\end{tabular}


Table 6B: High SES background subsample

\begin{tabular}{|c|c|c|c|c|c|c|}
\hline \multicolumn{7}{|l|}{ Men } \\
\hline Age & \multicolumn{2}{|c|}{ 40-50 age group } & \multicolumn{2}{|c|}{ 50-60 age group } & \multicolumn{2}{|c|}{ aggregate } \\
\hline Reform & 1.023 & 1.042 & 1.019 & 1.080 & 1.027 & 1.004 \\
\hline & $\begin{array}{c}(0.917- \\
1.142)\end{array}$ & $\begin{array}{c}(0.915- \\
1.187)\end{array}$ & $\begin{array}{c}(0.886- \\
1.172)\end{array}$ & $(0.903-1.291)$ & $\begin{array}{c}(0.953- \\
1.107)\end{array}$ & $\begin{array}{c}(0.926- \\
1.088)\end{array}$ \\
\hline Linear trend & & $x$ & & $x$ & & $x$ \\
\hline Deaths & 3,422 & 3,422 & 2,305 & 2,305 & 6,956 & 6,956 \\
\hline $\begin{array}{l}\text { Sample } \\
\text { size }\end{array}$ & 194,704 & 194,704 & 191,285 & 191,285 & 195,951 & 195,951 \\
\hline \multicolumn{7}{|l|}{ Women } \\
\hline Age & \multicolumn{2}{|c|}{ 40-50 age group } & \multicolumn{2}{|c|}{ 50-60 age group } & \multicolumn{2}{|c|}{ aggregate } \\
\hline Reform & $\begin{array}{c}1.035 \\
(0.899- \\
1.192)\end{array}$ & $\begin{array}{c}1.038 \\
(0.879- \\
1.227)\end{array}$ & $\begin{array}{c}0.840+ \\
(0.697- \\
1.012)\end{array}$ & $\begin{array}{c}0.904 \\
(0.739- \\
1.107)\end{array}$ & $\begin{array}{c}0.942 \\
(0.853- \\
1.040)\end{array}$ & $\begin{array}{c}0.939 \\
(0.844- \\
1.046)\end{array}$ \\
\hline Linear trend & & $x$ & & $x$ & & $\mathrm{x}$ \\
\hline Deaths & 2,228 & 2,228 & 1,577 & 1,577 & 4,450 & 4,450 \\
\hline $\begin{array}{l}\text { Sample } \\
\text { size }\end{array}$ & 185,206 & 185,206 & 182,981 & 182,981 & 185,850 & 185,850 \\
\hline
\end{tabular}

Note: The number of low SES and high SES background observations does not add up to the total number of observations in the first panel due to missing information on the father's education level

VII. C. The effects of the reform on hospitalization

Even if extra education does not significantly affect mortality, it may alter the health care consumption patterns of those affected by the reform, counteracting possible deteriorations in health that may result from better education (say because of increased consumption of alcohol or other unhealthy activities). In this case would then expect to see an increase in the incidence of hospitalizations among the reform group that is not accompanied by any significant mortality effects. Table 7 shows linear probability model estimates for the effect of the reform on the probability of being hospitalized for any cause between 1987 and 2006. We show results for the same groups based on parental SES, age and gender as for the mortality results in Table 3. Again, we show the results from two specifications, where one specification includes a linear trend interacted with a group dummy based on year of reform implementation. 
Table 7: Linear probability model estimates of the effect of the educational reform on hospitalizations.

\begin{tabular}{|c|c|c|c|c|c|c|}
\hline \multicolumn{7}{|l|}{ Men } \\
\hline & \multicolumn{2}{|c|}{ All } & \multicolumn{2}{|c|}{ Low SES } & \multicolumn{2}{|c|}{ High SES } \\
\hline Reform & $\begin{array}{c}-0.002 \\
(-0.006-0.002)\end{array}$ & $\begin{array}{c}-0.003 \\
(-0.007- \\
0.001)\end{array}$ & $\begin{array}{c}-0.001 \\
(-0.007- \\
0.005)\end{array}$ & $\begin{array}{c}-0.003 \\
(-0.01- \\
0.003)\end{array}$ & $\begin{array}{c}-0.002 \\
(-0.009- \\
0.005)\end{array}$ & $\begin{array}{r}0.000 \\
(-0.008- \\
0.009)\end{array}$ \\
\hline Mean & 0.53 & 0.53 & 0.54 & 0.54 & 0.49 & 0.49 \\
\hline Linear trends & & & & $\mathrm{x}$ & & $x$ \\
\hline Sample size & 745,330 & 745,330 & 323,374 & 323,374 & 195,991 & 195,991 \\
\hline \multicolumn{7}{|l|}{ Women } \\
\hline Reform & $\begin{array}{c}-0.001 \\
(-0.007-0.004)\end{array}$ & $\begin{array}{c}-0.002 \\
(-0.008- \\
0.004)\end{array}$ & $\begin{array}{c}0.001 \\
(-0.005- \\
0.008)\end{array}$ & $\begin{array}{c}-0.001 \\
(-0.007- \\
0.006)\end{array}$ & $\begin{array}{c}-0.001 \\
(-0.010- \\
0.008)\end{array}$ & $\begin{array}{r}-0.000 \\
(-0.010- \\
0.010)\end{array}$ \\
\hline Mean & 0.6 & 0.6 & 0.6 & 0.6 & 0.58 & 0.58 \\
\hline Trends & & & & X & & $x$ \\
\hline Sample size & 714,694 & 714,694 & 306,989 & 306,989 & 185,902 & 185,902 \\
\hline
\end{tabular}

Note: The number of low SES and high SES background observations does not add up to the total number of observations in the first panel due to missing information on the father's education level

Recognizing that the binary hospitalization might be too coarse to pick up differences in the frequency and the type of problem people get inpatient care for, we first test whether the reform affected the probability of hospitalization in any year. Second, we check if individuals who went through reform schools incurred lower average inpatient care costs using the CMS-HCC risk score adjustment. We interact the reform dummy with age to test for potentially different effects in age groups. Figures 3 and 4 below summarize the results. 
Figure 3: The effect of education reform on the probability of hospitalization by patient age.

Men

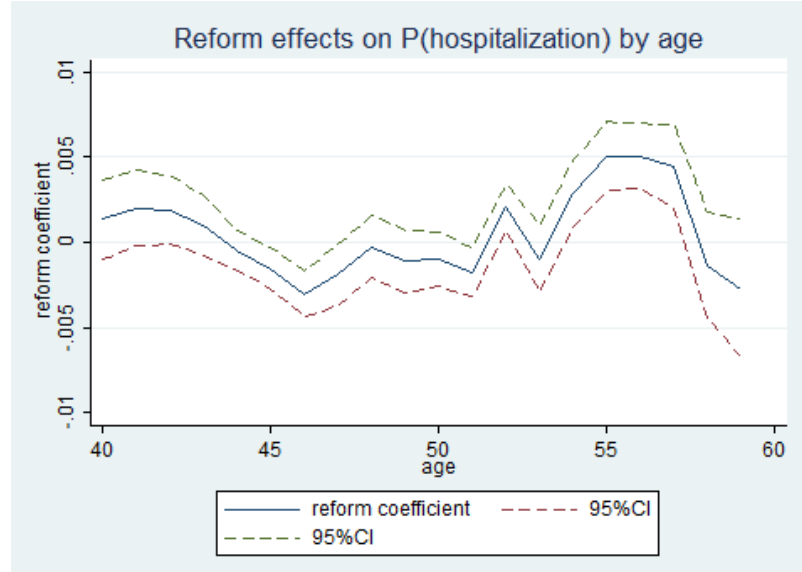

Women

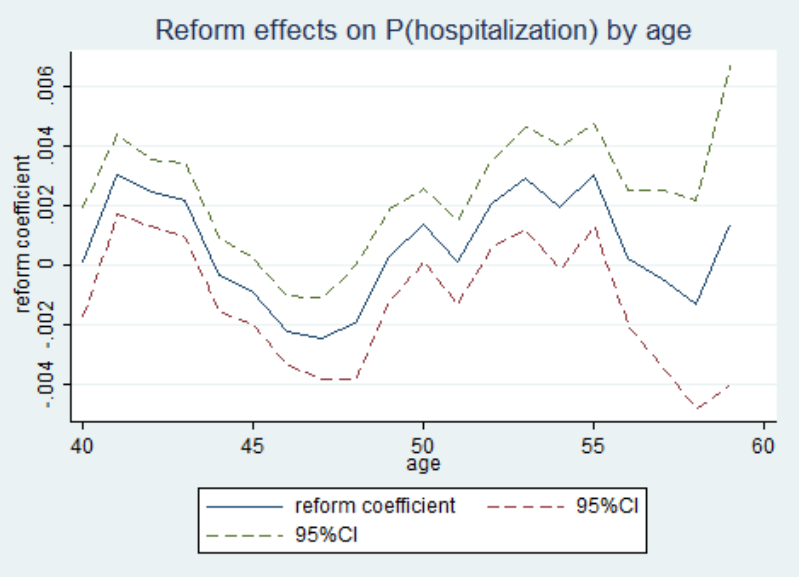

Figure 3 plots the coefficient estimates on the interaction term of the reform dummy with age dummies. The reference group for each reform*age dummy interaction are individuals of the same age who were not affected by the reform. The mean hospitalization rate for the reference group is 0.1 for males and 0.11 for females. Thus, relative to the comparison group, Swedish men who went through reformed schools are between 2.5\% less likely (around age 45) and 5\% more likely (around age 55) to be hospitalized. The corresponding numbers for women are slightly smaller in magnitude but the general trends across age groups are similar for the two sexes.

The most prominent finding that emerges from the results plotted in Figure 2 is that the reform effect is heterogeneous across age. Thus, analysis based on cross-sectional evidence fixing the age group, or analysis that captures the cumulative reform effects up to a fixed age do not reveal the whole story. This of course raises the question of whether there are further important effects at older ages we do not observe yet. 
In Figure 4 we plot the coefficient estimates on the age*reform interaction dummies from a regression where the CMS-HCC risk adjustment score is the dependent variable. In addition to the previous hospitalizations history, this score takes into account the average expenditure by ICD9 code and therefore is a more accurate predictor of health care costs than a simply binary indicator for hospitalizations.

Figure 4: The effect of education reform on expected health care costs based on hospitalization records.
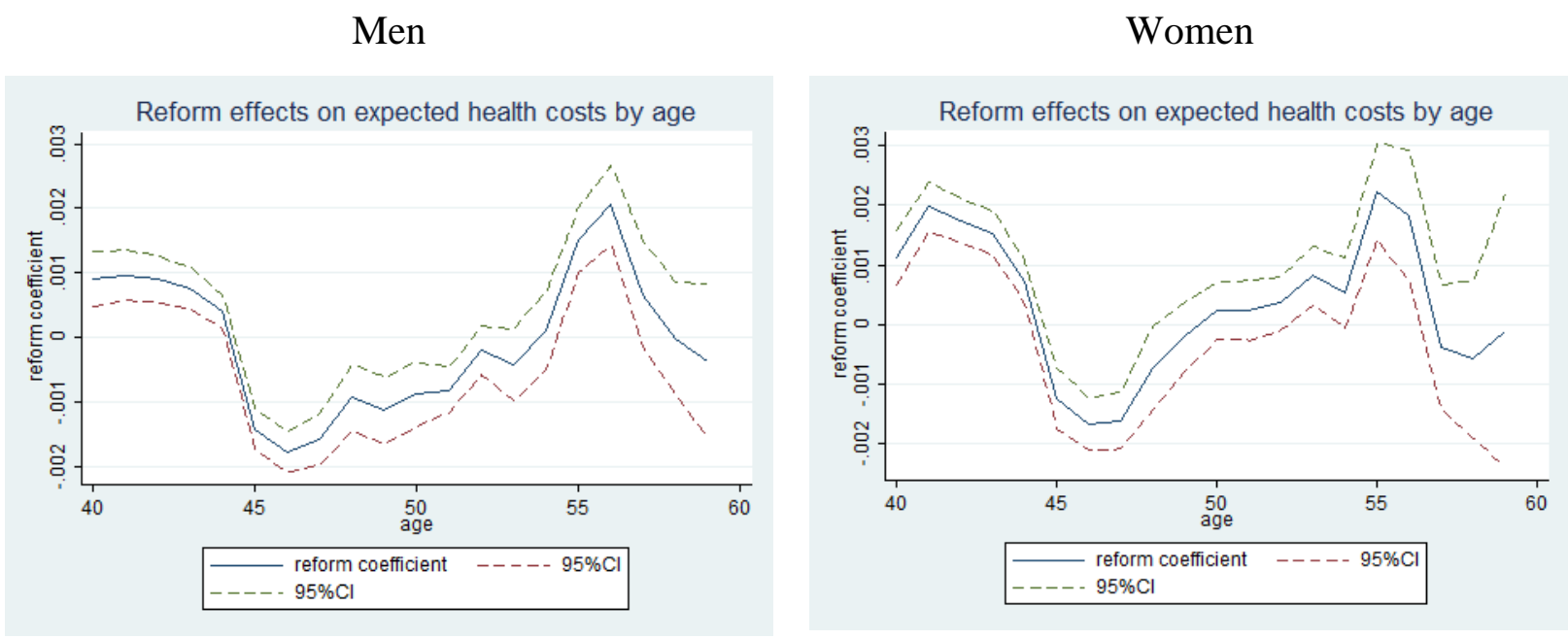

Figure 4 shows that the pattern of hospitalizations over time holds up in the cost estimates. The mean CMS-HCC risk score for Swedish men who were not treated to the reform is 0.026 , implying between $7.7 \%$ higher (around age 55) to 7\% lower (around age 47) costs among men who went through reform schools. For women, the corresponding numbers are between $4 \%$ higher (around age 42) to $4 \%$ lower (around age 47) costs among women who went through reform schools relative to others. The differences in costs are more pronounced than the differences in the probability of hospitalization, implying that the relative severity of the inpatient episode acts to exacerbate any differences implied by varying probabilities of 
hospitalization. Consistently, we find that negative health shocks are delayed by about a decade among both men and women who went to reform schools compared to their peers.

VII. D. The effects of the reform on exit from the labor force

Table 8 shows the results of the estimates of the effect of the reform on the timing of the exit from the labor force. The effect of the reform is restricted to men, who significantly delay their exit from the labor force as a result of the reform. The main effect can be attributed to those originating from homes with low educated fathers. The point estimates indicate an about 3 percent decrease in the probability to retire. Considering our results that the reform increased average years of schooling by about 3.3 months for boys from low SES families, this result is quite similar to the estimate of about 9 percent decreased exit rate from the labor market associated with one additional year of schooling reported in Table 3 .

Table 8: The effect of education reform on early exit from the labor force. Cox proportional hazard models. 95 percent confidence intervals in parentheses.

\begin{tabular}{lccc}
\hline & $(1)$ & $(2)$ & $(3)$ \\
& All & Low father's education & High father's education SES \\
\hline Men & & & \\
Reform & $0.9666^{*}$ & $0.9691^{*}$ & 0.9851 \\
& $(0.9510-0.9825)$ & $(0.9492-0.9895)$ & $(0.9535-1.0178)$ \\
Sample size & 741,022 & 318,914 & 177,483 \\
& & & \\
Women & & & 0.9992 \\
Reform & 0.9937 & 1.0119 & $(0.9676-1.0319)$ \\
Sample size & $(0.9689-1.0191)$ & $(0.9887-1.0358)$ & 168,305 \\
\hline
\end{tabular}

Note: + significant at $10 \% ;{ }^{* *}$ significant at $5 \% ;{ }^{*}$ significant at $1 \%$

VII. E. The effects of the reform on mortality by cause of death

It is possible that the overall small and insignificant results for mortality from all causes grouped together mask important differences between mortality by cause. To explore this 
possibility we break down mortality due to different underlying causes of death. We do the same thing for the hospitalization analysis, by showing the results for different diagnoses separately.

The two main causes of death are circulatory diseases and cancer. We expect to find the largest effect for circulatory diseases, since in the descriptive analysis we found it to have a stronger education gradient than mortality in cancer. Table 9 shows the Cox proportional hazard competing risk estimates of the effect of the reform for these separate causes of death and Table 9 shows the linear probability estimates of the effect of the reform on the probability of being hospitalized as a result of being diagnosed with circulatory diseases or cancer, respectively. Again, we present results separately for the low and high SES groups.

None of the results presented in Table 9 or 10 are significantly different from zero on the 5 percent level. The point estimate for low SES males, whose educational attainments were more strongly affected by the reform and have the highest mortality rate in circulatory diseases, indicate a reduction in mortality, but is not statistically significant. The point estimates of the reform effect for females are marginally significant and with an unexpected sign also in the low SES group. However, when looking at these results, one has to bear in mind that the mortality rate in circulatory diseases among men is more than three times higher compared to women. 
Table 9: Cox proportional hazard competing risk estimates of the effect of the education reform on mortality in circulatory diseases and cancer, respectively; 95 percent confidence intervals in parentheses.

\begin{tabular}{|c|c|c|c|c|}
\hline & \multicolumn{2}{|c|}{ Men } & \multicolumn{2}{|c|}{ Women } \\
\hline $\begin{array}{l}\text { Reform } \\
\text { Deaths }\end{array}$ & $\begin{array}{c}\text { Cancer } \\
1.025 \\
(0.932-1.126) \\
6,480\end{array}$ & $\begin{array}{c}\text { Circulatory } \\
0.989 \\
(0.909-1.076) \\
7,116\end{array}$ & $\begin{array}{c}\text { Cancer } \\
1.016 \\
(0.949-1.086) \\
8,977\end{array}$ & $\begin{array}{c}\text { Circulatory } \\
1.200+ \\
(0.998-1.442) \\
1,983\end{array}$ \\
\hline \multicolumn{5}{|c|}{ Low SES background } \\
\hline $\begin{array}{l}\text { Reform } \\
\text { Deaths } \\
\text { Sample size }\end{array}$ & $\begin{array}{c}1.042 \\
(0.904-1.201) \\
2,657 \\
323,291\end{array}$ & $\begin{array}{c}0.935 \\
(0.812-1.076) \\
2,844 \\
323,291\end{array}$ & $\begin{array}{c}1.036 \\
(0.927-1.158) \\
3,583 \\
306,883\end{array}$ & $\begin{array}{c}1.173+ \\
(0.980-1.403) \\
776 \\
306,883\end{array}$ \\
\hline \multicolumn{5}{|c|}{ High SES background } \\
\hline $\begin{array}{l}\text { Reform } \\
\text { Deaths } \\
\text { Sample size }\end{array}$ & $\begin{array}{c}1.002 \\
(0.830-1.209) \\
1,460 \\
195,951\end{array}$ & $\begin{array}{c}1.02 \\
(0.852-1.220) \\
1,267 \\
195,951\end{array}$ & $\begin{array}{c}0.931 \\
(0.797-1.089) \\
2,010 \\
185,850\end{array}$ & $\begin{array}{c}1.208 \\
(0.793-1.841) \\
345 \\
185,850\end{array}$ \\
\hline
\end{tabular}

Note: The number of low SES and high SES background observations does not add up to the total number of observations in the first panel due to missing information on the father's education level

Table 10: The effect of the reform on hospitalizations for circulatory diseases and cancer. Linear probability models. 95 percent confidence intervals in parentheses.

\begin{tabular}{lcccccc}
\hline & \multicolumn{3}{c}{ Men } & \multicolumn{3}{c}{ Women } \\
\hline \multirow{3}{*}{ Reform } & Cancer & Circulatory & Other & Cancer & Circulatory & Other \\
& -0.00079 & 0.00113 & 0.00023 & 0.00024 & -0.0009 & 0.00046 \\
& $(-0.002-0.0003)$ & $(-0.002-0.004)$ & $(-0.0011-$ & $(-0.002-0.002)$ & $(-0.003-0.001)$ & $(-0.0003-$ \\
Mean & 0.084 & $0.002)$ & & & $0.001)$ \\
Sample & 745,032 & 745,032 & 714,427 & 714,427 & 714,427 & 714,427 \\
size & & & & & & \\
$R^{2}$ & 0.00612 & 0.01350 & 0.00633 & 0.00826 & 0.00826 & 0.00826 \\
\hline
\end{tabular}

Low SES background

\begin{tabular}{lcccc}
\hline & \multicolumn{2}{c}{ Men } & \multicolumn{2}{c}{ Women } \\
\hline Reform & Cancer & Circulatory & Cancer & Circulatory \\
& -0.00004 & 0.00230 & 0.00085 & 0.00074 \\
Mean & $(-0.00187-0.002)$ & $(-0.0016-0.006)$ & $(-0.002-0.004)$ & $(-0.003-0.004)$ \\
Sample & 0.08 & 0.29 & 0.15 & 0.22 \\
size & 323,291 & 323,291 & 306,883 & 306,883 \\
$R^{2}$ & & & & \\
\hline
\end{tabular}


High SES background

\begin{tabular}{|c|c|c|c|c|}
\hline & \multicolumn{2}{|c|}{ Men } & \multicolumn{2}{|c|}{ Women } \\
\hline & Cancer & Circulatory & Cancer & Circulatory \\
\hline Reform & -0.00077 & 0.00143 & 0.00015 & -0.00255 \\
\hline & $(-0.003-0.002)$ & $(-0.004-0.007)$ & $(-0.004-0.004)$ & $(-0.0067-0.002)$ \\
\hline Mean & 0.08 & 0.25 & 0.15 & 0.19 \\
\hline Sample & 195,932 & 195,932 & 185,850 & 185,850 \\
\hline size & & & & \\
\hline$R^{2}$ & 0.00993 & 0.01619 & 0.01014 & 0.01020 \\
\hline
\end{tabular}

Note: The number of low SES and high SES background observations does not add up to the total number of observations in the first panel due to missing information on the father's education level

Table 11 presents results on Cox proportional hazard competing risk estimates of the effect of the reform on mortality in preventable and treatable diseases. Table 12 shows the corresponding results for hospitalizations in these diagnoses. From the descriptive analysis we know that diagnoses referred to as preventable and treatable causes have a stronger education gradient than other diagnoses.

The results reveal a diverging picture for males and females. For males, we find no support for improved health from preventable diagnoses. In fact, there is a marginally significant increase in mortality in preventable causes of death. However, since this increase is primarily referred to high SES individuals who are not so strongly affected by the reform, this result should be interpreted cautiously. Also, the hospitalization results in Table 12 do not give support to increased health problems due to preventable diagnoses. We note however that in their analysis of the education reform on earnings Meghir and Palme (2005) found that men coming from high SES backgrounds were the "losers" from the reform. Earnings among the treated in this subgroup were lower due to the reform; they attribute this to the dilution of the quality of education for what used to be the elite educated group in the old system..

For females, there is a marginally significant decrease in mortality due to preventable causes of death. This result is supported by an equally marginally significant decrease in hospitalization in diagnoses referred to preventable causes. The most likely explanation for this 
result is that for women, education works by affecting health behaviors that lead to premature mortality from preventable diseases. Improved health behaviors reduce both the incidence of hospitalizations and the mortality rate from lung cancer and liver cirrhosis. The pattern is sustained in females coming from all SES backgrounds.

Why do we find divergent evidence across the two genders? There are at least two plausible explanations. First, the effects might reverse later in life for males and our time window is simply not broad enough. Second, while the Swedish surgeon general warning that “smoking kills" came only in 1977, when our youngest cohort was already 20 years old and likely had formed health habits, women were warned about the detrimental effects of smoking and drinking during pregnancy at least since the 1960s. Thus, for those women who had children, there was at least one instance when additional health information may have caused women with more education to alter health behaviors.

Table 11: Cox proportional hazard competing risk estimates of the effect of the education reform on mortality in preventable and treatable diseases. 95 percent confidence intervals in parentheses.

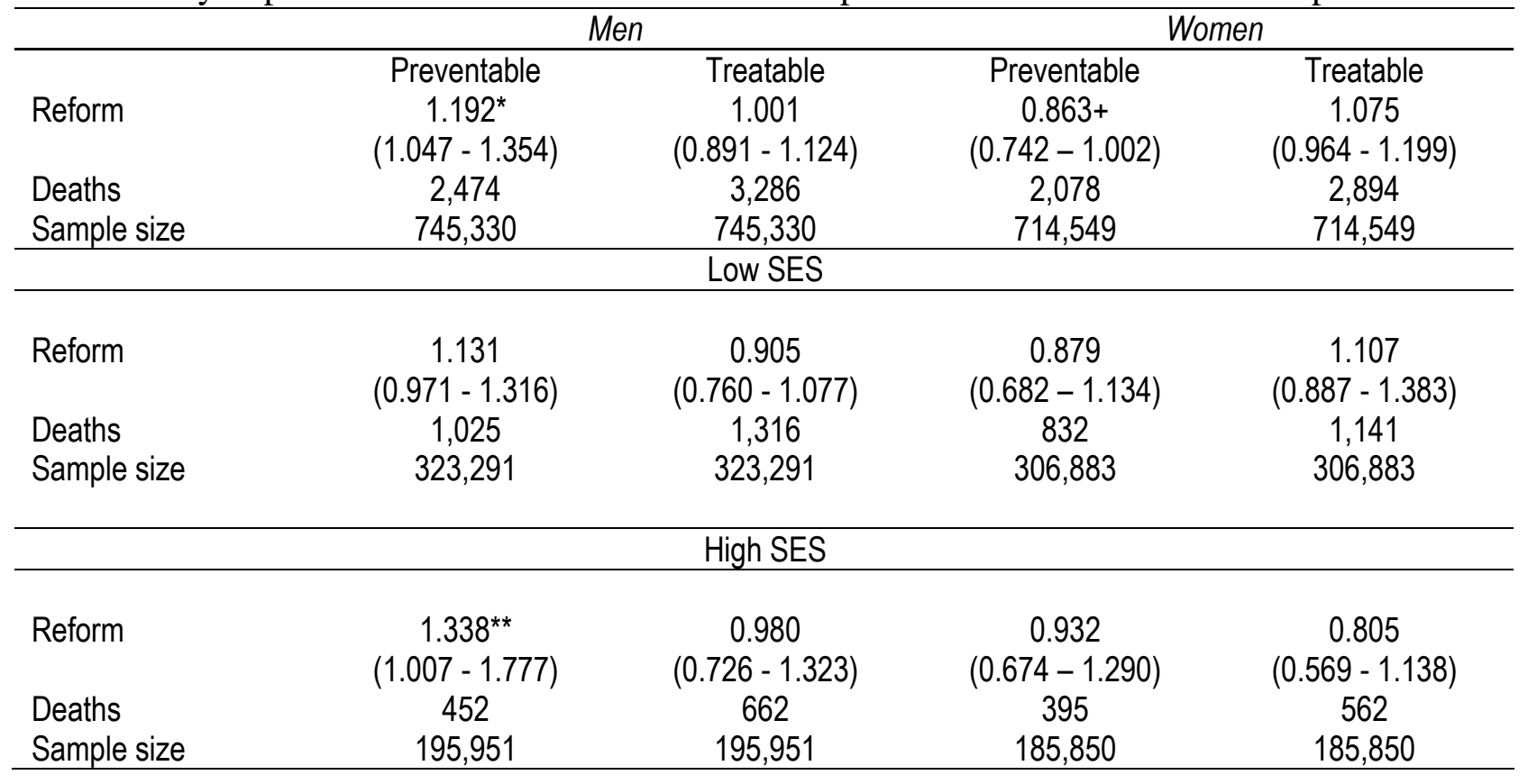


Table 12: The effect of the reform on hospitalizations for preventable and treatable causes. 95 percent confidence intervals in parentheses.

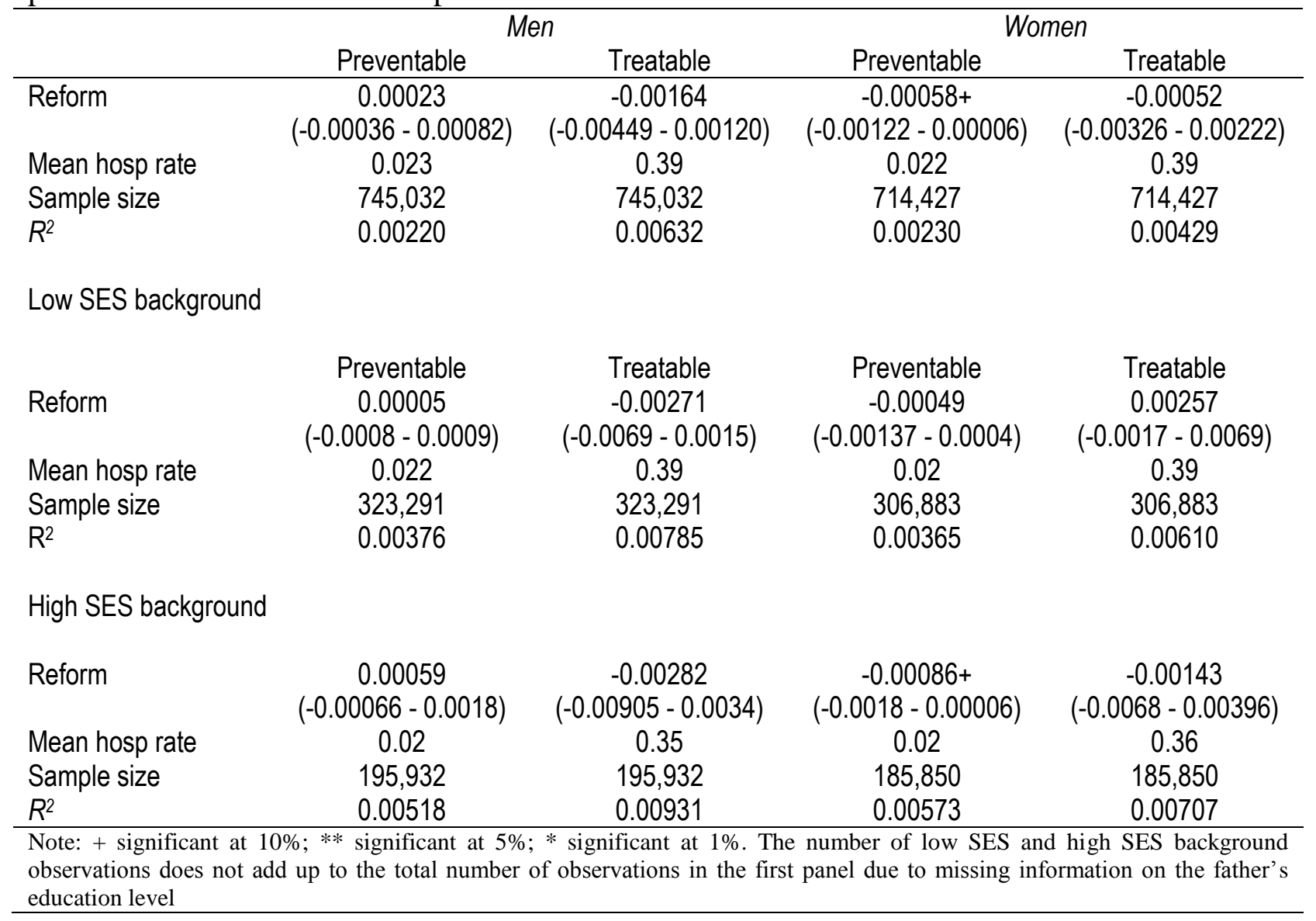

VII. F. The effects of the reform on the incidence and mortality from breast cancer

Finally, we consider the effect of the school reform on the prevalence and mortality from breast cancer. Breast cancer, which is the most common form of cancer diagnosis for women in Sweden, is a "welfare disease", since it is well known from numerous previous studies that the prevalence of breast cancer increases with years of schooling and income, both across individuals as well as across countries with different per capita income and education levels. However, it is also well known that the survival probability in breast cancer is positively related to the education level of diagnosed women. Data for breast cancer diagnosis is obtained by matching our sample to the Swedish Cancer Register. 
We first consider the effect of education on the probability of receiving a diagnosis of breast cancer and the hazard of death from breast cancer. Table 13 shows that our data matches up with this general pattern from previous studies: the prevalence of diagnosed cancers increases with years of schooling, but mortality in breast cancer is not significantly related to education, perhaps due to the counteracting effect mentioned above. Table 14 shows the relation between reform assignment and probability of getting a breast cancer diagnosis as well as the probability of dying from breast cancer for all women and separately for low SES individuals. The results reveal a significant relation between reform assignment and the probability of being diagnosed with breast cancer for low SES individuals; and a significant increase in mortality from breast cancer in the full sample ${ }^{21}$.

Table 13: The effect of education on diagnosis and death from breast cancer (women only). Robust standard errors in parentheses.

\begin{tabular}{lcc}
\hline & Diagnosed & Died \\
\hline Years of completed education & $0.001^{*}$ & 0.992 \\
Mean of outcome variable & $(0.001-0.001)$ & $(0.965-1.019)$ \\
\hline Sample size & 0.039 & 0.005 \\
$R^{2}$ & 679,445 & 679,445 \\
& 0.004 & 0.004
\end{tabular}

+ significant at $10 \% ;{ }^{* *}$ significant at $5 \% ;{ }^{*}$ significant at $1 \%$

Table 14: Educational reform and the diagnosis and deaths from breast cancer (women only). Robust standard errors in parentheses.

\begin{tabular}{lcccc}
\hline & \multicolumn{2}{c}{ Diagnosed breast cancer } & \multicolumn{2}{c}{ Died breast cancer } \\
\hline & All & Low SES & All & Low SES \\
Reform & 0.001 & $0.002^{* *}$ & $1.160^{* *}$ & 1.169 \\
& $(0.001)$ & $(0.001)$ & $(1.022-1.318)$ & $(0.950-1.439)$ \\
Mean of outcome & 0.039 & 0.037 & 0.005 & 0.0045 \\
variable & & & \\
Sample size & 713,320 & 306,463 & 713,320 & 306,463 \\
$R^{2}$ & 0.004 & 0.005 & & \\
Robust standard errors in parentheses & & & \\
\hline+ significant at $10 \%{ }^{* *}$ significant at $5 \% ;{ }^{*}$ significant at $1 \%$ & & & \\
\hline
\end{tabular}

\footnotetext{
${ }^{21}$ In the analyses we exclude all women who have received a diagnosis of breast cancer pre-1985 to avoid selection bias. Our mortality data start in 1985 . Survival following a breast cancer diagnosis could be related to the reform.
} 


\section{Sensitivity Analysis}

To minimize the potential effect from underlying municipality-level trends that were not picked up by the reform-year trends, we consider only birth cohorts within a year of the reform implementation. As these children were exposed to more similar conditions while growing up, we should capture a more robust estimate of the reform impact. We first consider all-cause mortality and then we focus on mortality by different causes. Table A5 in the Appendix presents the results. The estimates from the constrained sample show a consistent picture with the full sample results. All signs are consistent, and most of the magnitudes of the hazard rates are also similar.

In a further robustness check, we plot the incidence of deaths in the reform and nonreform groups by gender over time. As Figure 5 shows, the incidence of deaths was not always "smooth" over time depending on reform status and gender. Spikes in death incidence indicate that there were a disproportionately high number of individuals belonging to the group who died in a year. For example, in 1994 there were a disproportionately high number of reform men who died, and in 1991 there was a spike in deaths among women affected by the reform. To avoid possible contamination of estimates emanating from random events that affected one of the groups disproportionately, we repeat the mortality analysis after discarding all deaths from 1991, 1994, 1995, and after 2002. The results are presented in Table A6 in the Appendix. There are no significant differences with the main estimates. 
Figure 5: Number of deaths by year and reform status.

Men no reform

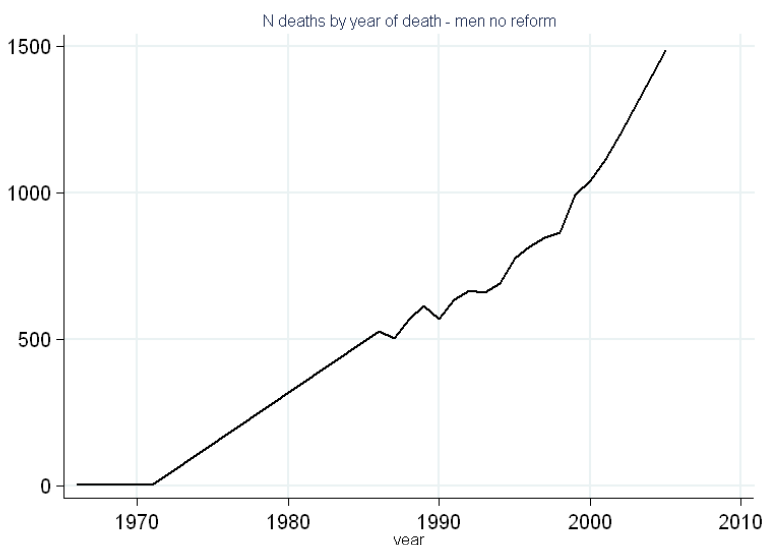

Women no reform

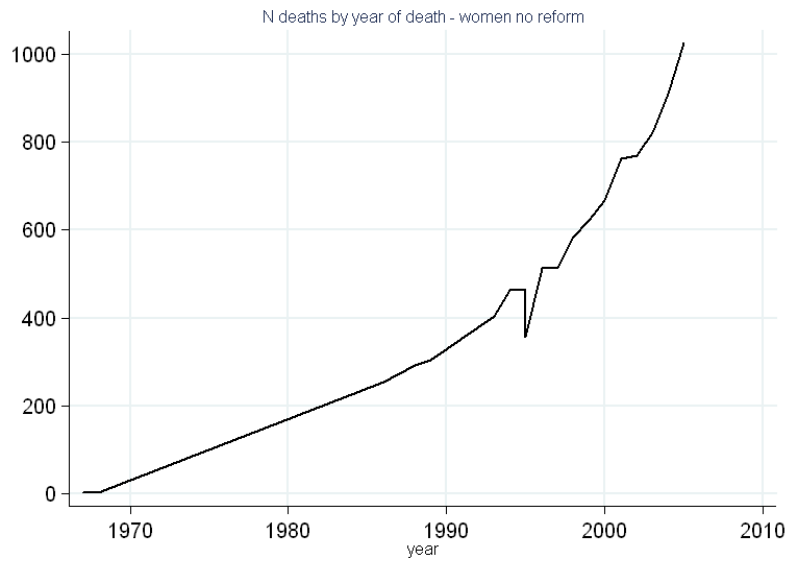

Men reform

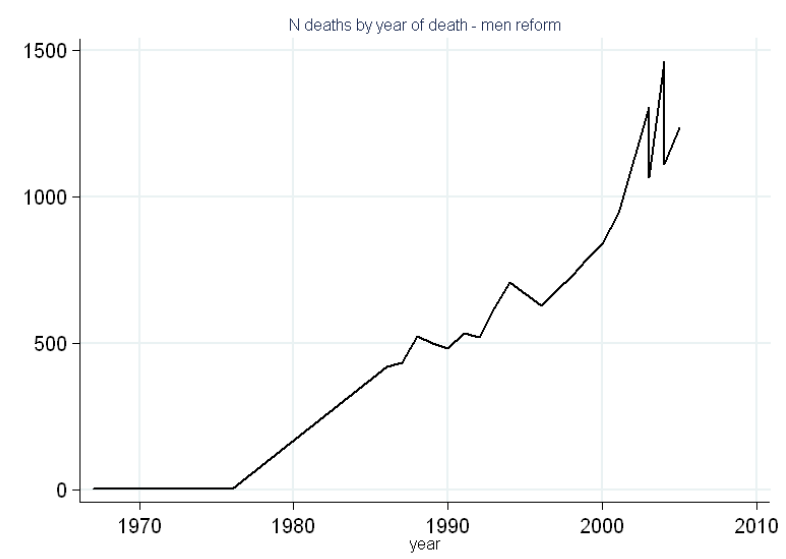

Women reform

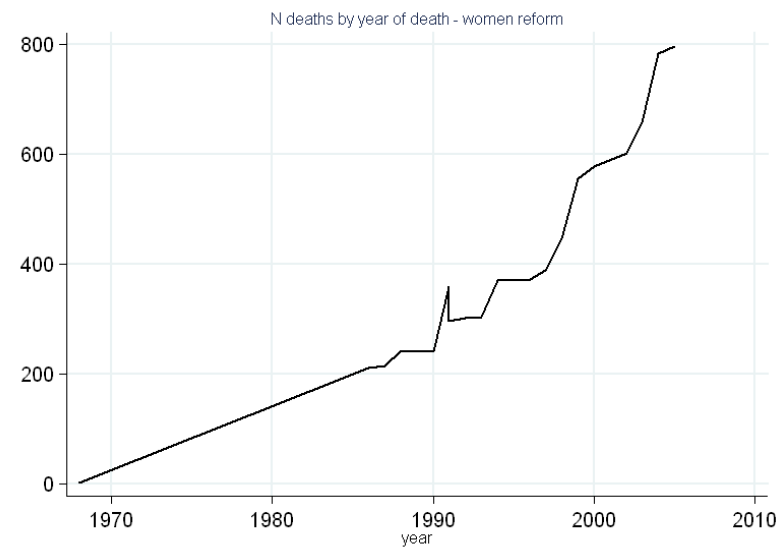

We also test whether measurement error in the treatment variable is attenuating our estimates of the reform effect on mortality. For a random $10 \%$ subset of the population of individuals born in 1948 and in 1953 - and on the $5^{\text {th }}, 15$, and $25^{\text {th }}$ of every month - we have reform status as reported by the school. ${ }^{22}$ Table A7 reports the results from Cox proportional hazard models of mortality using these data. The statistical precision is limited as the number of observations is severely reduced compared with the full population. However, the estimates are

\footnotetext{
22 The data come from the Individual Statistics (IS) project of the Institute for Education at the University of Gothenburg
} 
not qualitatively different from the ones we reported using the full population. Missmeasurement of the treatment variable is not significantly affecting the reported estimates.

We also test whether excluding parishes that had already implemented the reform by 1947 or implemented it late enough to affect only the last cohort (1957) affects the results. The sample used for the Cox regressions in table A8 comprises only individuals who were born in parishes that contribute both reform and non-reform cohorts to the sample. The parish must have at least one cohort of each type to be represented in this subsample. As table A9 shows, this restriction does not change our main results. On the contrary, it yields tighter confidence intervals.

Finally, we calculate the 10-year mortality rate to exactly match the mortality calculations used in Lleras-Muney (2005). We first present the overall mortality rate, and then we split out mortality from preventable causes (lung cancer and liver cirrhosis) only. The genderspecific mortality rate is calculated on the municipality-cohort level. We use OLS estimations with reform status as an indicator treatment variable. Appendix table A9 presents the results. Neither the plain difference-in-differences models, nor the models including linear groupspecific trends show a significant effect of the educational reform on overall mortality (male or female). These estimates are in line with our results obtained from the Cox proportional hazard models. We find no evidence of large and persistent effects of the compulsory education reform on later life health and mortality up to age sixty. The results on preventable mortality also confirm our main findings presented above.

\section{Conclusions}

We analyze the effect of an education reform that was implemented as a social experiment in Sweden on affected cohorts born between 1946 and 1957 on mortality, 
hospitalizations and early exit from the labor market. Our results on mortality can be compared to those of previous studies also studying the effect of compulsory schooling laws on mortality. We find that the reform delayed mortality for men in the age group 40-49 to ages 50-60, and that this delay was, as expected, driven by the low SES background group. However, we find that the reform had very small effects on overall health as measured by mortality up to age 60 . Using the 95 percent confidence intervals we could exclude treatment effects on mortality above 5 percent across all individuals, and above 6.8 percent in the low SES group. Considering that the reform prolonged average years of schooling in the low SES group by on average $0.2-0.3$ years, these results are much more in line with the small effects found in Clark and Royer (2010), than the about 30 percent reduction in mortality for each year of additional schooling found in LlerasMuney (2005).

There are several reasons why our results may differ from those of Lleras-Muney apart from the fact that she estimates a LATE parameter, rather than an intention to treat parameter as in this study. ${ }^{23}$ First, they refer to different periods in time. The cohorts under study in this paper are between 20 and 55 years younger than those in the Lleras-Muney study. It is conceivable that the effects of education were stronger in older cohorts born and raised in the USA, since they, among other things, were much more likely to be exposed to child labor or bad working conditions in early years. Second, there are several important institutional differences between Sweden and the US. Among other things of relevance in this context, the observed wage differentials between educational groups are much larger in the US and, as opposed to the US, Sweden has a universal health care system covering all citizens. Finally, the Lleras-Muney estimates could have been influenced by various differences in e.g. health care provision

\footnotetext{
${ }^{23}$ Even if we divide our mortality coefficients by the first stage coefficients ( 0.3 in the low male SES background group), we still cannot match a $30 \%$ decrease in mortality attributable to the educational reform.
} 
between US states, which were not the case in this study since all individuals were active on the same labor and health care markets.

The relation between educational attainment and health involves several, partly counteracting processes. By also analyzing intermediate health-related outcomes results this paper sheds some light over the workings of these underlying mechanisms. Previous studies have stressed the importance of education in the process of being able to allocate consumption in order to achieve a more favorable health outcome, the so called allocative efficiency. Improvement in allocative efficiency would most likely show up in decreases in the incidence of preventable diseases. In this study, we did not find evidence for this being the case in the male sub-sample, since neither mortality in causes of death nor hospitalization in diagnoses related to preventable disease changed in a way supporting such increase. For women, we find some evidence for increased allocative efficiency, since both mortality and hospitalization in preventable diseases decreased. However, this change was counteracted by increased prevalence of breast cancer, known from previous studies to have a positive education gradient.

The strongest result on intermediate outcomes was on delayed exit from the labor market for males. Almost all Swedes who exit from the labor market before age 65 use some form of insurance program requiring health problems for eligibility, since the abolition of the right to disability insurance for labor market reasons in 1991 (see e.g. Palme and Svensson, 2004, or Karlström, Palme and Svensson, 2008). However, these estimates should be interpreted cautiously, considering the fact that utilization of the disability insurance also depends on personal drive to remain in the labor force, work environment and economic incentives to stay employed - factors that could very well also be affected by the education reform. For evaluating 
the fiscal implication, as well as effects on individual wellbeing, the estimated effect is important, irrespective of the driving mechanism. 


\section{References}

Clark, Damon and Heather Royer. 2010. "The Effect of Education on Adult Health and Mortality: Evidence from Britain” NBER Working Paper 16013.

Cutler, David, and A. Lleras-Muney. 2006. Education and health: evaluating theories and evidence. In J.S. House, R.F. Schoeni, G.A. Kaplan, and H. Pollack, eds., The Health Effects of Social and Economic Policy, New York: Russell Sage Foundation.

Cutler, David, and A. Lleras-Muney. 2011 "Education and Health” Unpublished manuscript.

Cutler, David, Angus Deaton and A. Lleras-Muney. 2006. "The Determinants of Mortality," Journal of Economic Perspectives, Vol. 20, No. 3, (with David Cutler and Angus Deaton)

Grossman, Michael (2006), "Education and Nonmarket Outcomes." Handbook of the Economics of Education, edited by Eric Hanushek and Finis Welch. Amsterdam: North-Holland, Elsevier Science.

Holmlund, H. (2007) “A Researcher's Guide to the Swedish Compulsory School Reform”, Working paper 9/2007, Swedish Institute for Social Research, Stockholm University.

Glied, Sherry and Adriana Lleras-Muney. 2008. "Health Inequality, Education and Medical Innovation" Demography, Volume 45, Number 3

Karlström, A., M. Palme and I. Svensson .2008. "The Employment Effect of Stricter Rules for Eligibility to DI: Evidence from a Natural Experiment in Sweden" Journal of Public Economics, 92, 2071-2082.

Lleras-Muney, A. 2005. "The Relationship Between Education and Adult Mortality in the United States," Review of Economic Studies, 72, 189-221.

Mazumder, Bhashkar. 2008. "Does Education Improve Health: A Reexamination of the Evidence from Compulsory Schooling Laws," Economic Perspectives, 33(2), 2008

Meghir, Costas and Marten Palme (2005) "Educational Reform, Ability, and Family Background" American Economic Review, 95(1), 414-424.

Oreopoulos, Philip (2006) "Estimating Average and Local Average Treatment Effects of Education when Compulsory School Laws Really Matter" American Economic Review, 96(1), 152-175.

Palme, M. and I. Svensson (2004) "Income Security Programs and Retirement in Sweden", in Jonathan Gruber and David Wise (eds.) "Social Security and Retirement Around the World: 
Micro-estimates", 2004, Chicago University Press: Chicago

Gregory C. Pope, John Kautter, Melvin J. Ingber, Sara Freeman, Rishi Sekar, and Cordon Newhart. 2011. "Evaluation of the CMS-HCC Risk Adjustment Model" available at https://www.cms.gov/MedicareAdvtgSpecRateStats/downloads/Evaluation_Risk_Adj_Model_20 11.pdf (accessed March, 2012).

Socialstyrelsen (2009a). The Swedish Cause of Death Registry. Sweden, Stockholm. 2009.

Socialstyrelsen (2009b). The Swedish National Patient Register. Inpatient diseases in Sweden 1987-2007. Sweden, Stockholm. 2009.

Spasojevic, Jasmina (2010) "Effects of Education on Adult Health in Sweden: Results from a Natural Experiment" in Daniel Slottje, Rusty Tchernis (ed.) Current Issues in Health Economics (Contributions to Economic Analysis, Volume 290), Emerald Group Publishing Limited, 179199. 
APPENDIX TABLES

Table A1: Number of individuals in a cohort by reform status of the municipality of birth

\begin{tabular}{lllll}
\multicolumn{3}{c}{ No reform } & \multicolumn{2}{c}{ Reform } \\
\hline 1946 & Alive in 1985 & Died by 2005 & Alive in 1985 & Died by 2005 \\
1947 & 120,808 & 7,097 & 16,034 & 962 \\
1948 & 113,341 & 6,114 & 20,999 & 1,124 \\
1949 & 92,009 & 4,505 & 40,632 & 2,009 \\
1950 & 79,238 & 3,479 & 48,316 & 2,182 \\
1951 & 64,571 & 2,540 & 57,410 & 2,387 \\
1952 & 58,112 & 2,217 & 58,490 & 2,249 \\
1953 & 44,314 & 1,615 & 72,447 & 2,473 \\
1954 & 34,340 & 1,088 & 82,395 & 2,647 \\
1955 & 27,765 & 833 & 84,900 & 2,429 \\
1956 & 4,433 & 106 & 109,936 & 2,969 \\
1957 & 781 & 16 & 114,436 & 2,886 \\
\hline
\end{tabular}

Table A2: ICD 9 and ICD10 codes groups used to establish different causes of death and hospitalization

\begin{tabular}{lll} 
Cause & ICD9 & ICD10 \\
\hline Treatable causes of death & & \\
Tuberculosis & $010-018,137$ & A15-A19. B90 \\
Malignant neoplasm of cervix uteri & 180 & C53 \\
Chronic rheumatic heart disease & $393-398$ & I05-I09 \\
All respiratory diseases & $460-519$ & J00-J99 \\
Asthma & 493 & J45, J46 \\
Appendicitis & $540-543$ & K35-K38 \\
Abdominal hernia & $550-553$ & K40-K46 \\
Hypertensive and cerebrovascular disease & $401-405,430-438$ & I10-I15, I60-169 \\
Chollelthiasis and cholecystitis & $574,575.0,575.1$ & K80-K81 \\
Maternal deaths & $630-676$ & O00-099 \\
& & \\
Cancers, excl lung cancer and cervical cancer & $140-239$ & C00-C99; D00-D48 \\
$\begin{array}{l}\text { Diseases of the circulatory system, excl chronic } \\
\text { rheumatic heart disease, hypertensive and }\end{array}$ & $390-459$ & I00-1999 \\
cardiovascular disease & & \\
$\begin{array}{l}\text { Preventable causes of death } \\
\text { Lung cancer }\end{array}$ & & \\
Cirrhosis of liver & 162 & C33-C34 \\
\hline
\end{tabular}


Table A3: Mortality by different cause as a fraction of total mortality by reform status of the municipality of birth

\begin{tabular}{lrrrr}
\hline & \multicolumn{2}{c}{ Reform } & \multicolumn{2}{c}{ No reform } \\
\hline N dead by 2005 (total) & 26,862 & $\%$ total deaths & 29,613 & $\%$ total deaths \\
$\begin{array}{l}\text { Preventable } \\
\text { Treatable }\end{array}$ & 1,962 & $7,304 \%$ & 2,587 & $8,736 \%$ \\
$\begin{array}{l}\text { Circulatory (excluding } \\
\text { hypertension; rheumatic heart }\end{array}$ & 2,834 & $10,550 \%$ & 3,336 & $11,265 \%$ \\
$\begin{array}{l}\text { disease) } \\
\text { Cancer (excluding lung cancer }\end{array}$ & & & & \\
$\begin{array}{l}\text { and cervical cancer) } \\
\text { Breast Cancer }\end{array}$ & 3,921 & $14,597 \%$ & 5,169 & $17,455 \%$ \\
\hline
\end{tabular}

Table A4: The effects of education on male mortality - levels of completed education

\begin{tabular}{llll}
\hline & $(1)$ & $(2)$ & $(3)$ \\
\hline Age & $50-60$ & $40-50$ & Aggregate \\
\hline Vocational & $0.796^{*}$ & $0.808^{*}$ & $0.805^{*}$ \\
& $(0.739-0.857)$ & $(0.692-0.944)$ & $(0.740-0.877)$ \\
Secondary & $0.491^{*}$ & $0.454^{*}$ & $0.500^{*}$ \\
& $(0.412-0.584)$ & $(0.339-0.608)$ & $(0.419-0.598)$ \\
College & $0.422^{*}$ & $0.335^{*}$ & $0.419^{*}$ \\
& $(0.370-0.481)$ & $(0.275-0.409)$ & $(0.371-0.473)$ \\
PhD & $0.289^{*}$ & $0.367^{*}$ & $0.306^{*}$ \\
& $(0.188-0.444)$ & $(0.172-0.782)$ & $(0.211-0.446)$ \\
Sample size & 527574 & 691620 & 691756 \\
\hline
\end{tabular}

The effects of education on female mortality - levels of completed education

\begin{tabular}{llll}
\hline & $(1)$ & $(2)$ & $(3)$ \\
\hline Age & $50-60$ & $40-50$ & Aggregate \\
\hline Vocational & $0.664^{*}$ & $0.617^{*}$ & $0.664^{*}$ \\
& $(0.615-0.718)$ & $(0.524-0.727)$ & $(0.620-0.710)$ \\
Secondary & $0.507^{*}$ & $0.412^{*}$ & $0.486^{*}$ \\
& $(0.387-0.663)$ & $(0.237-0.714)$ & $(0.379-0.624)$ \\
College & $0.462^{*}$ & $0.413^{*}$ & $0.459^{*}$ \\
& $(0.421-0.507)$ & $(0.333-0.511)$ & $(0.419-0.502)$ \\
PhD & $0.339^{*}$ & 0.638 & $0.387^{*}$ \\
& $(0.210-0.545)$ & $(0.248-1.643)$ & $(0.256-0.586)$ \\
Sample size & 519874 & 680300 & 680416 \\
Robust 95\% confidence intervals in parentheses; + significant at 10\%; & ${ }^{*}$ significant at $5 \% ;{ }^{*}$ significant at \\
1\%; standard errors clustered at the municipality of birth & \\
\hline
\end{tabular}


Table A5: The effect of education reform on the mortality of cohorts within a year of the reform. Cox proportional hazard regressions; stratified at the municipality of birth level A. Men

\begin{tabular}{llll}
\hline Men & \multicolumn{3}{c}{ All-cause mortality } \\
\hline Age & $50-60$ & $40-50$ & Aggregate \\
Reform & 1.010 & 0.931 & 0.960 \\
& $(0.910-1.121)$ & $(0.829-1.046)$ & $(0.889-1.036)$ \\
& \multicolumn{2}{c}{} \\
& & Preventable disease mortality \\
Reform & $1.438^{* *}$ & 0.796 & 1.064 \\
& $(1.022-2.022)$ & $(0.556-1.139)$ & $(0.847-1.336)$ \\
Sample size & 239285 & 277211 & 279417 \\
\hline
\end{tabular}

B: Women

\begin{tabular}{|c|c|c|c|}
\hline Women & \multicolumn{3}{|c|}{ All cause mortality } \\
\hline Age & $50-60$ & $40-50$ & Up to 60 \\
\hline \multirow[t]{3}{*}{ Reform } & 0.999 & 1.098 & 1.067 \\
\hline & $(0.869-1.150)$ & $(0.948-1.272)$ & $(0.980-1.163)$ \\
\hline & \multicolumn{3}{|c|}{ Circulatory disease mortality } \\
\hline \multirow[t]{3}{*}{ Reform } & 1.157 & 1.127 & 1.072 \\
\hline & $(0.782-1.712)$ & $(0.778-1.633)$ & $(0.837-1.372)$ \\
\hline & \multicolumn{3}{|c|}{ Preventable disease mortality } \\
\hline \multirow[t]{2}{*}{ Reform } & 0.956 & 1.026 & 0.976 \\
\hline & $(0.630-1.453)$ & $(0.649-1.620)$ & $(0.759-1.256)$ \\
\hline Sample size & 231606 & 266655 & 267784 \\
\hline \multicolumn{4}{|c|}{$\begin{array}{l}\text { Robust } 95 \% \text { confidence intervals in parentheses; + significant at } 10 \% ;{ }^{* *} \text { significant at } 5 \% ;{ }^{*} \text { significant at } \\
1 \% \text {; standard errors clustered by municipality of birth }\end{array}$} \\
\hline
\end{tabular}


Table A6: Analysis of male mortality excluding 1994 and the period post 2002. Cox proportional hazard regressions, stratified at the municipality of birth

\begin{tabular}{|c|c|c|c|}
\hline Age & $50-60$ & $40-50$ & Aggregate \\
\hline \multirow[t]{2}{*}{ Reform } & $\begin{array}{l}1.063 \\
(0.979-1.153)\end{array}$ & $\begin{array}{l}0.954+ \\
(0.906-1.004)\end{array}$ & $\begin{array}{l}0.989 \\
(0.952-1.026)\end{array}$ \\
\hline & & Cancer & \\
\hline \multirow[t]{2}{*}{ Reform } & $\begin{array}{l}1.135+ \\
(0.990-1.302)\end{array}$ & $\begin{array}{l}0.948 \\
(0.852-1.055)\end{array}$ & $\begin{array}{l}1.011 \\
(0.933-1.097)\end{array}$ \\
\hline & \multicolumn{3}{|c|}{ Circulatory disease mortality } \\
\hline \multirow[t]{2}{*}{ Reform } & $\begin{array}{l}0.992 \\
(0.824-1.194)\end{array}$ & $\begin{array}{l}0.939 \\
(0.821-1.074)\end{array}$ & $\begin{array}{l}0.970 \\
(0.883-1.065)\end{array}$ \\
\hline & \multicolumn{3}{|c|}{ Preventable disease mortality } \\
\hline Reform & $\begin{array}{l}1.450^{*} \\
(1.135-1.852)\end{array}$ & $\begin{array}{l}1.026 \\
(0.842-1.251)\end{array}$ & $\begin{array}{l}1.162^{* *} \\
(1.010-1.336)\end{array}$ \\
\hline Sample size & 501777 & 671090 & 677075 \\
\hline
\end{tabular}


Analysis of female mortality excluding 1991 and 1995. Cox proportional hazard regressions, stratified at the municipality of birth

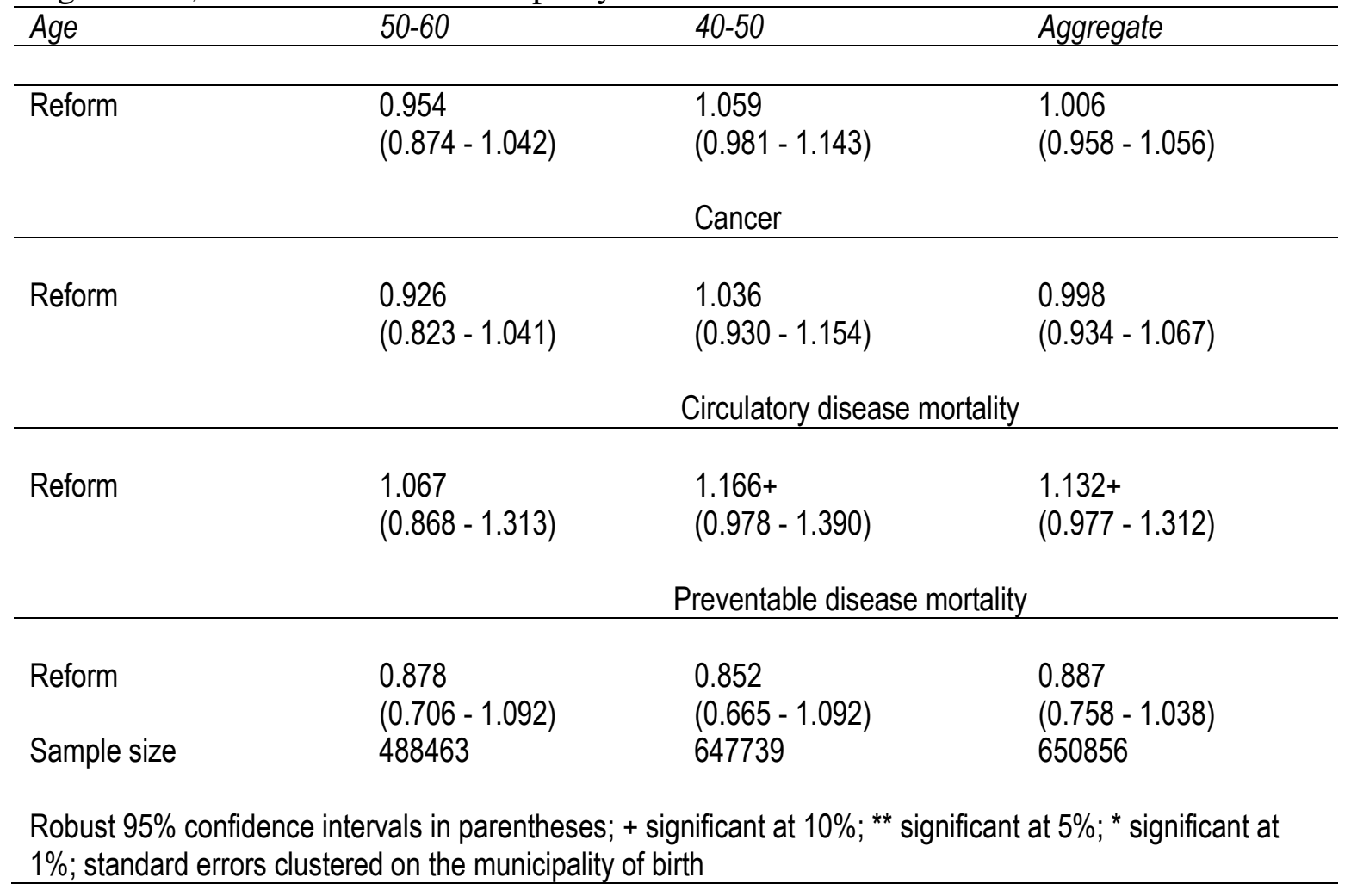

Table A7: The effect of school reform on mortality: limited sample with school-reported reform status for a random selection of the 1948 and 1953 cohorts; Cox proportional hazard models, stratified at the municipality of birth

Men

\begin{tabular}{llll}
\hline & $(1)$ & $(2)$ & $(3)$ \\
\hline Age & $40-50$ & $50-60$ & Aggregate \\
Reform & 0.880 & 1.201 & 0.980 \\
& $(0.613-1.265)$ & $(0.876-1.647)$ & $(0.749-1.282)$ \\
\hline Sample size & 10615 & 10373 & 10685 \\
\hline
\end{tabular}

Women

\begin{tabular}{llll}
\hline & $(1)$ & $(2)$ & $(3)$ \\
\hline Age & $40-50$ & $50-60$ & Aggregate \\
Reform & 1.063 & 0.919 & 0.959 \\
& $(0.752-1.503)$ & $(0.541-1.562)$ & $(0.732-1.256)$ \\
Sample size & 10263 & 10093 & 10315 \\
Robust 95\% confidence intervals in parentheses; + significant at $10 \% ;{ }^{* *}$ significant at $5 \% ;{ }^{*}$ significant at \\
1\%; standard errors clustered at the municipality of birth
\end{tabular}


Table A8: Education reform and mortality - using only parishes that switch reform status during the period 1947-1955; Cox proportional hazard regression, stratified at the municipality of birth

\begin{tabular}{|c|c|c|c|}
\hline Age & $40-50$ & $50-60$ & aggregate \\
\hline Reform & $\begin{array}{l}0.953+ \\
(0.906-1.002)\end{array}$ & $\begin{array}{l}1.096^{*} \\
(1.024-1.172)\end{array}$ & $\begin{array}{l}0.996 \\
(0.961-1.032)\end{array}$ \\
\hline Sample size & 631489 & 472490 & 637156 \\
\hline \multicolumn{4}{|l|}{ Women } \\
\hline Age & $40-50$ & $50-60$ & aggregate \\
\hline Reform & $\begin{array}{l}1.057 \\
(0.968-1.154)\end{array}$ & $\begin{array}{l}0.950 \\
(0.867-1.040)\end{array}$ & $\begin{array}{l}1.007 \\
(0.957-1.061)\end{array}$ \\
\hline Sample size & 609395 & 459636 & 612186 \\
\hline \multicolumn{4}{|c|}{$\begin{array}{l}\text { Robust } 95 \% \text { confidence intervals in parentheses; }+ \text { significant at } 10 \% ;{ }^{* *} \text { significant at } 5 \% \text {; }{ }^{*} \text { significant at } \\
1 \% \text {; standard errors clustered at the municipality of birth }\end{array}$} \\
\hline
\end{tabular}

Table A9: Educational reform and the 10-year mortality rate; ordinary least squares regressions

\begin{tabular}{|c|c|c|c|c|}
\hline Men & Total & Preventable cause & Total & Preventable cause \\
\hline Reform & $\begin{array}{l}-0.00004 \\
(-0.00035- \\
0.00028)\end{array}$ & $\begin{array}{l}0.0001+ \\
(-0.00001-0.00020)\end{array}$ & $\begin{array}{l}0.00001 \\
(-0.00036- \\
0.00038)\end{array}$ & $\begin{array}{l}0.00009+ \\
(-0.00002-0.00021)\end{array}$ \\
\hline Linear trend & NO & NO & YES & YES \\
\hline Mean mortality & 0.019 & 0.019 & 0.019 & 0.019 \\
\hline Sample size & 26565 & 26565 & 26520 & 26520 \\
\hline$R^{2}$ & 0.15396 & 0.05082 & 0.15391 & 0.05113 \\
\hline Women & Total & Preventable cause & Total & Preventable cause \\
\hline Reform & $\begin{array}{l}-0.00006 \\
(-0.00040- \\
0.00029)\end{array}$ & $\begin{array}{l}-0.0001+ \\
(-0.00023-0.00001)\end{array}$ & $\begin{array}{l}0.00004 \\
(-0.00032- \\
0.00039)\end{array}$ & $\begin{array}{l}-0.0001+ \\
(-0.00022-0.00002)\end{array}$ \\
\hline Linear trend & NO & NO & YES & YES \\
\hline Mean mortality & 0.015 & 0.015 & 0.015 & 0.015 \\
\hline Sample size & 22185 & 22185 & 22147 & 22147 \\
\hline$R^{2}$ & 0.15992 & 0.05958 & 0.16029 & 0.06002 \\
\hline \multicolumn{5}{|c|}{$\begin{array}{l}\text { Robust } 95 \% \text { confidence intervals in parentheses; + significant at } 10 \% ;{ }^{* *} \text { significant at } 5 \% ;{ }^{*} \text { significant at } \\
1 \% \text {; standard errors clustered at the municipality of birth }\end{array}$} \\
\hline
\end{tabular}

